\title{
Strategies for Engineering Photosynthesis for Enhanced Plant Biomass Production
}

\author{
Wataru Yamori
}

\begin{abstract}
Crop productivity would have to increase by $60-110 \%$ compared with the 2005 level by 2050 to meet both the food and energy demands of the growing population. Although more than $90 \%$ of crop biomass is derived from photosynthetic products, photosynthetic improvements have not yet been addressed by breeding. Thus, it has been considered that enhancing photosynthetic capacity is considered a promising approach for increasing crop yield. Now, we need to identify the specific targets that would improve leaf photosynthesis to realize a new Green Revolution. This chapter summarizes the various genetic engineering approaches that can be used to enhance photosynthetic capacity and crop productivity. The targets considered for the possible candidates include Rubisco, Rubisco activase, enzymes of the Calvin-Benson cycle, and $\mathrm{CO}_{2}$ transport, as well as photosynthetic electron transport. Finally, it describes the importance of considering ways to improve photosynthesis not under the stable environmental conditions already examined in many studies with the aim of improving photosynthetic capacity, but under natural conditions in which various environmental factors, and especially irradiation, continually fluctuate.
\end{abstract}

Keywords Calvin-Benson cycle $\cdot \mathrm{CO}_{2}$ assimilation $\cdot \mathrm{CO}_{2}$ transport $\cdot$ Electron transport $\cdot$ Photosynthesis $\cdot$ Rubisco

\section{Introduction}

Crop productivity would have to increase by $60-110 \%$ compared with the 2005 level by 2050 to meet both the food and energy demands of the growing population (Tilman et al. 2011; Alexandratos and Bruinsma 2012). At the same time, the $\mathrm{CO}_{2}$ concentration in the atmosphere is increasing and is predicted to reach $550 \mu \mathrm{mol} /$ mol by 2050 (IPCC 2013; Ballantyne et al. 2012), which will lead to an increase in air temperature. Thus, it is considered that approaches designed to improve plant

\footnotetext{
W. Yamori $(\bowtie)$

Institute for Sustainable Agro-Ecosystem Services, Graduate School of Agricultural and Life

Sciences, The University of Tokyo, Tokyo, Japan

e-mail: yamori@g.ecc.u-tokyo.ac.jp
} 
biomass and crop yield should take account of global climate change and the predicted future environmental conditions.

It has been reported that in most cases leaf photosynthetic rate does not correlate positively with grain yield (Richards 2000). Some critical reviews suggest that improving photosynthesis would not be a useful strategy for enhancing crop productivity (Gu et al. 2014; Sinclair et al. 2004). However, a meta-analysis of several studies on elevated $\mathrm{CO}_{2}$ experiments in various crops has indicated that any strategy for increasing photosynthesis can enhance crop yield (Ainsworth et al. 2008). Similarly, it has been proposed that altering photosynthetic electron transport rates by manipulating the cytochrome $\mathrm{b}_{6} / \mathrm{f}$ complex can improve both the photosynthetic capacity and crop yield of transgenic plants (Yamori et al. 2016a; Fig. 1). Enhancing photosynthetic capacity in plants is now considered a promising approach for increasing crop yield and decreasing the atmospheric concentration of $\mathrm{CO}_{2}$, which is the primary component of greenhouse gases.

This chapter summarizes the various genetic engineering approaches that can be used to enhance photosynthetic capacity and plant production. The targets considered for the possible candidates include Rubisco, Rubisco activase, enzymes of the Calvin-Benson cycle, and $\mathrm{CO}_{2}$ transport, as well as photosynthetic electron

Fig. 1 Relationship between $\mathrm{CO}_{2}$ assimilation rate at a $\mathrm{CO}_{2}$ concentration of $390 \mu \mathrm{mol} / \mathrm{mol}$, total plant dry weight at the final stage, and grain yield in rice. Wild type: open triangles; transgenic plants that contain variable amounts of Rieske FeS protein in the cytochrome $\mathrm{b}_{6} / \mathrm{f}$ complex from 10 to $100 \%$ of wild-type levels: filled circles. The regression lines are shown

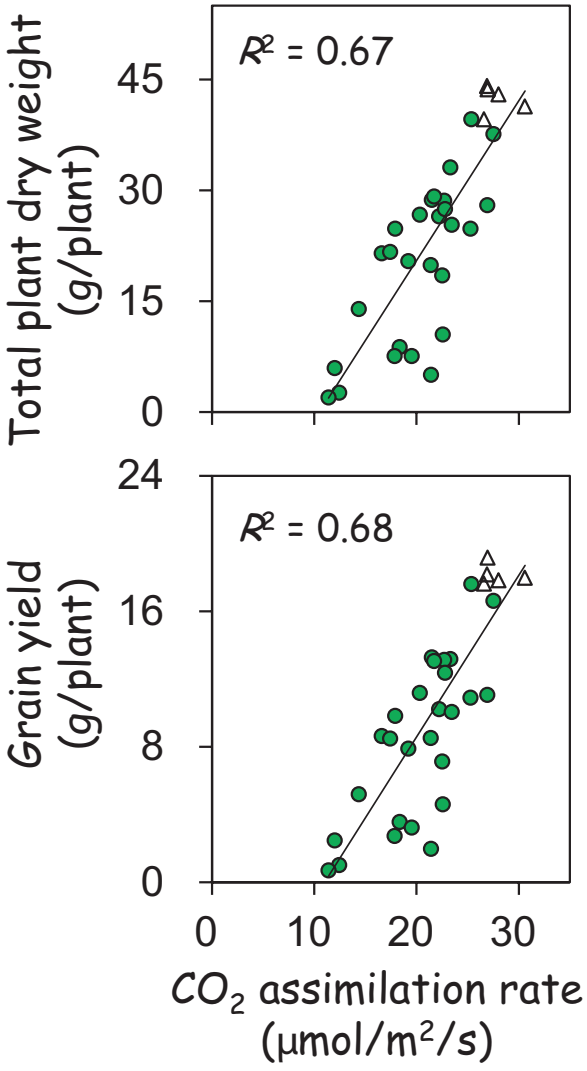


transport. Finally, it describes the importance of considering ways to improve photosynthesis not under the stable environmental conditions already examined in many studies with the aim of improving photosynthetic capacity, but under natural conditions in which various environmental factors, and especially irradiation, continually fluctuate.

\section{Improving Rubisco Performance}

\subsection{Rubisco Kinetics}

Rubisco (ribulose-1,5-bisphosphate carboxylase/oxygenase) is an enzyme involved in the first step of $\mathrm{CO}_{2}$ fixation in photosynthesis (Fig. 2). Rubisco has a low catalytic efficiency and can only fix approximately two to four $\mathrm{CO}_{2}$ molecules per second per active site in higher $\mathrm{C}_{3}$ plants. Thus, $20-30 \%$ of the nitrogen in the leaves of $\mathrm{C}_{3}$ plants is invested in Rubisco to compensate for its low activity (Spreitzer and Salvucci 2002). There is a strong positive correlation between leaf Rubisco content and photosynthetic rate (Evans 1989; Makino et al. 1997; Wright et al. 2004), indicating that Rubisco would be rate-limiting as regards photosynthesis at the current $\mathrm{CO}_{2}$ concentration. Rubisco can fix $\mathrm{CO}_{2}$ in photosynthesis and $\mathrm{O}_{2}$ in photorespiration (Fig. 2). Photosynthetic $\mathrm{CO}_{2}$ fixation produces two molecules of phosphoglycerate (PGA) for every carbon fixed, while photorespiration produces one PGA and one phosphoglycolate (PGO). PGO must be recycled to PGA, with a loss of $\mathrm{CO}_{2}$ and $\mathrm{NH}_{3}$ via a photorespiratory pathway. Although the released $\mathrm{CO}_{2}$ may be re-fixed by the chloroplasts and the $\mathrm{NH}_{3}$ re-assimilated in the leaves (Morris et al. 1988; Busch et al. 2013), photorespiration is considered to be a wasteful reaction. Thus, it may be possible to improve photosynthetic efficiency by modifying Rubisco in plants to increase catalytic activity and/or decrease oxygenation rate.

In plants, Rubisco usually consists of two types of protein subunit: a chloroplastencoded large subunit, which contains the active site, and nuclear-encoded small subunits. The introduction of Rubisco variants with high specificity values such as that from $\mathrm{C}_{4}$ plants and cyanobacteria into plants could improve the photosynthetic efficiency of crop plants. Previously, transgenic tobacco plants expressing Flaveria bidentis $\left(\mathrm{C}_{4}\right)$ and F. pringlei $\left(\mathrm{C}_{3}\right)$ Rubisco large subunit chimeras revealed that the substitution of methionine-309 with isoleucine is responsible for increases in the carboxylation rate of Rubisco (Whitney et al. 2011). However, the $\mathrm{CO}_{2}$ assimilation rate and plant growth were lower in transgenic plants than in wild-type plants since transformants decreased the Rubisco content of the former compared with the latter. Lin et al. (2014) successfully produced transgenic tobacco plants with functional Rubisco by replacing the Rubisco with the large and small subunit genes found in cyanobacterium. The transgenic plants increased the $\mathrm{CO}_{2}$ assimilation rate per Rubisco content, but they grew more slowly than wild-type plants. Thus, although mutated forms of Rubisco protein have been achieved in tobacco plants, the 


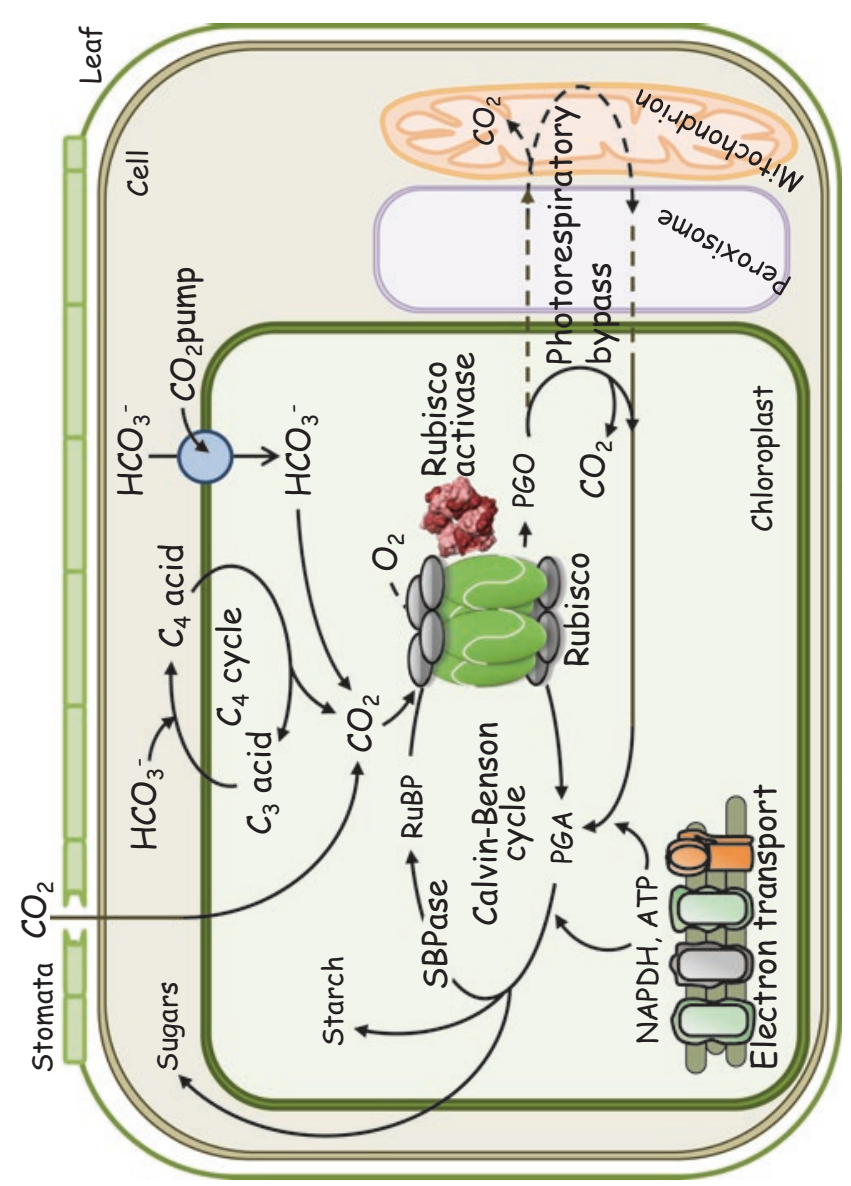

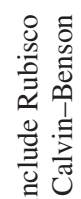

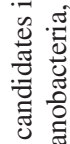

엉

के

을

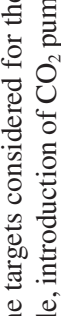

웡

.ํี่

氖

을 음

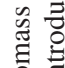

응.

芩每

흔

马्ठ

言

to

क है

흥

范

के

들

苛 흥

ब른

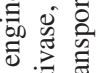

ᄒ 워

\& 80

50:

可

क ज

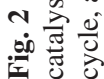


site-directed mutagenesis of Rubisco has as yet been largely unsuccessful (Furbank et al. 2015). If the replacement of the Rubisco variants of $\mathrm{C}_{3}$-type Rubisco (i.e., a low catalytic turnover rate for Rubisco, $k c a t$, and a low Michaelis-Menten constant, $\mathrm{Km}$; a high $\mathrm{Km}$ for $\mathrm{CO}_{2}$ indicates low $\mathrm{CO}_{2}$ affinity) with $\mathrm{C}_{4}$-type or cyanobacteriatype Rubisco variants (i.e., high $k c a t$ and high $\mathrm{Km}$ ) is successful, the transgenic $\mathrm{C}_{3}$ plants could enhance their photosynthetic efficiency and plant growth toward the high- $\mathrm{CO}_{2}$ world of the near future.

Although the evidence from transplastomic studies of Rubisco indicates that the catalytic variability resides within its large subunit, the importance of its small subunits to Rubisco catalysis has also attracted attention. Recent success has demonstrated that the introduction of a $\mathrm{C}_{4}$-Rubisco small subunit $(\mathrm{rbcS})$ gene from sorghum into rice successfully produced chimeric Rubisco with a greater $k c a t$ in transgenic rice (Ishikawa et al. 2011). This breakthrough could provide future ways to engineer Rubisco in various important crops such as wheat and rice.

\subsection{Photorespiration Bypass}

Rubisco is a dual-function enzyme that fixes $\mathrm{CO}_{2}$ or $\mathrm{O}_{2}$, and these functions are known as photosynthesis and photorespiration, respectively. While photosynthesis results in a net fixation of $\mathrm{CO}_{2}$, the photorespiratory pathway requires ATP and releases previously fixed $\mathrm{CO}_{2}$ (Fig. 3). The photorespiration rate is affected by the concentration of $\mathrm{CO}_{2}$ in the chloroplast $\left(\mathrm{C}_{\mathrm{c}}\right)$ relative to the $\mathrm{O}_{2}$ concentration, and increases with increasing temperature. At current atmospheric $\mathrm{CO}_{2}$ concentrations and a temperature of $30^{\circ} \mathrm{C}$, the rate of photorespiratory $\mathrm{CO}_{2}$ release from the mitochondria is approximately $25 \%$ of the $\mathrm{CO}_{2}$ assimilation rate (Sage et al. 2012). Thus, lowering photorespiratory flux could alleviate the decrease in photosynthetic efficiency in $\mathrm{C}_{3}$ plants. However, manipulations aimed at blocking the photorespiratory pathway had detrimental effects on plant growth (Kozaki and Takeba 1996; Walker et al. 2016). Nonetheless, advances have been made for engineering plants that can make better use of the $\mathrm{CO}_{2}$ released from photorespiration via photorespiratory bypasses (Carvalho et al. 2012; Kebeish et al. 2007; Maier et al. 2012; Peterhansel et al. 2013).

To date, three different strategies have been designed to bypass photorespiration in $\mathrm{C}_{3}$ plants (Fig. 3). The first pathway was engineered using Escherichia coli encoded genes from the glycerate pathway that convert glycolate to glycerate and release $\mathrm{CO}_{2}$ within the chloroplast (Kebeish et al. 2007; Peterhansel et al. 2013). Transgenic plants engineered with this pathway decreased photorespiration and enhanced photosynthesis, resulting in improved plant growth (Kebeish et al. 2007). With the second approach, transgenic plants engineered with a glycolate catabolic cycle designed to oxidize glycolate to $\mathrm{CO}_{2}$ in chloroplasts (Fig. 3) displayed higher photosynthetic rates and greater plant growth (Maier et al. 2012; Peterhansel et al. 2013). These observations show that shifting glycolate metabolism from the photorespiratory pathway via peroxisome and mitochondria to the chloroplast is 
$\rightarrow$ Chloroplastic glycerate bypass

$\longrightarrow$ Chloroplastic glycolate oxidation bypass

$\rightarrow$ Peroxisomal glycerate bypass

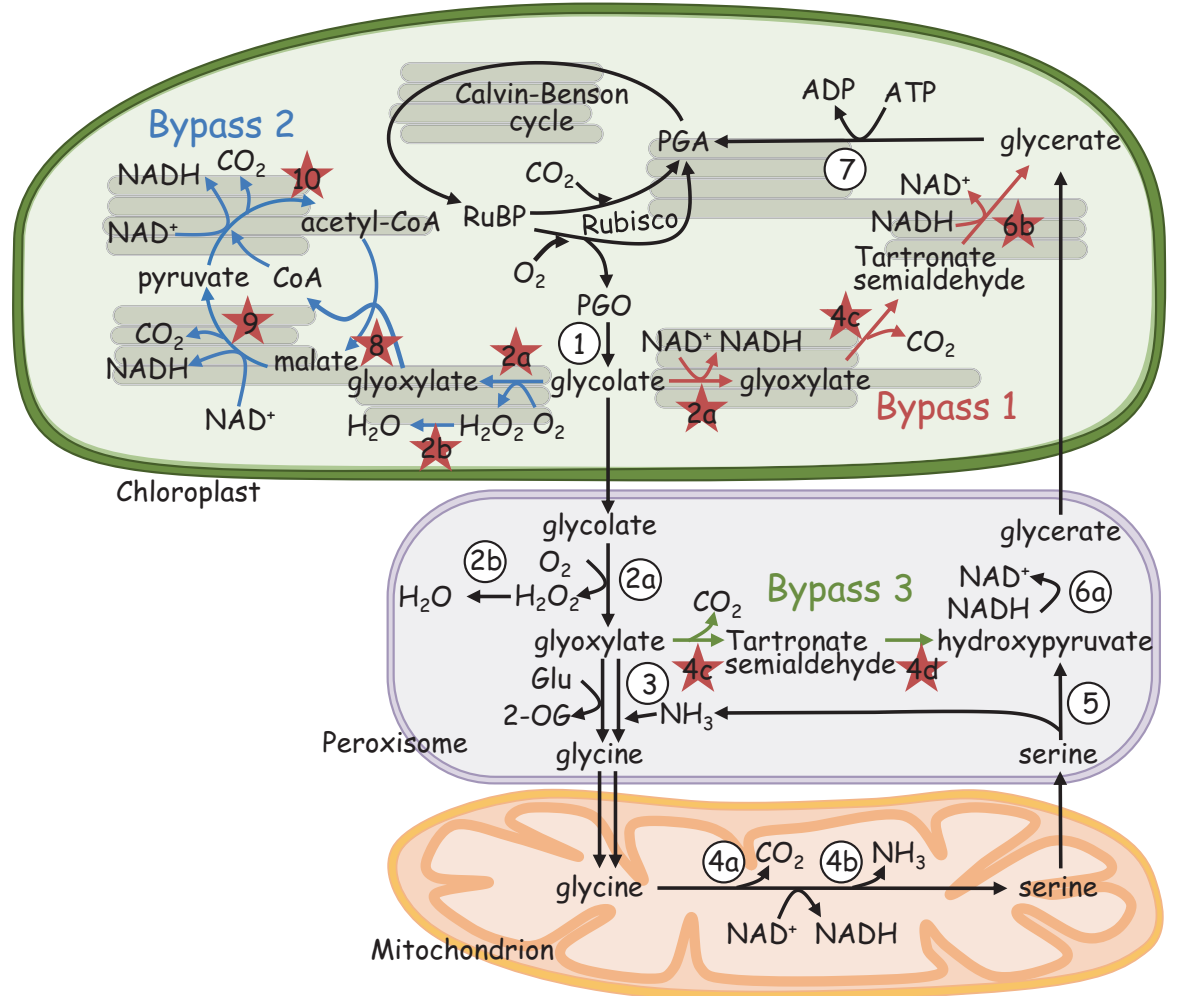

Fig. 3 Schematic diagram of photorespiration in plants (black), with three bypasses to minimize photorespiratory expenses engineered in plants (red, blue, green). Enzymatic reactions or metabolite transport steps are indicated by arrows. (1) phosphogycolate phosphatase, (2a) glycolate oxidase, (2b) catalase, (3) glyoxylate/glutamate aminotransferase, (4a) glycine decarboxylase, (4b) serine hydroxymethyl transferase, $(4 \mathrm{c})$ glyoxylate carboligase, which catalyzes the decarboxylation of glyoxylate and ligation to a second molecule of glyoxylate to form tartronate semialdehyde, (4d) hydroxypyruvate isomerase, (5) serine/glyoxylate aminotransferase, (6a) hydroxypyruvate reductase in photorespiration, (6b) tartronic semialdehyde reductase, (7) glycerate kinase, (8) malate synthase, (9) NADP-malic enzyme, (10) pyruvate dehydrogenase. Rubisco ribulose-1,5-bisphosphate carboxylase/oxygenase; $R u B P$ ribulose-1,5-bisphosphate; $P G A$ phosphoglycerate; $P G O$ phosphoglycolate

beneficial for plants and can enhance photosynthesis. The third bypass was created by short-circuiting the original $\mathrm{C}_{2}$ cycle to avoid $\mathrm{NH}_{3}{ }^{+}$release and to prevent energy loss in its refixation (Carvalho et al. 2012). The glyoxalase in peroxisomes can be converted to hydroxypyruvate by introducing glyoxylate carboligase and hydroxypyruvate isomerase from $E$. coli into the plant peroxisomes, and feeding them back to the $\mathrm{C}_{2}$ cycle (Fig. 3) (Carvalho et al. 2012; Peterhansel et al. 2013). However, in transgenic plants, the photorespiratory cycle has not yet been completely bypassed 
and the short-circuiting led to damage of the photosynthetic apparatus and thus deleterious phenotypes (Carvalho et al. 2012).

Facilitating photorespiratory flux through the overexpression of subunits of glycine decarboxylase (GDC), which produces $\mathrm{CO}_{2}$ by the photorespiratory process, could be another approach for improving photorespiration (Timm et al. 2016). GDC comprises four proteins, three enzymes (P-protein, T-protein, and L-protein), and a small lipoylated protein known as H-protein, which has no catalytic activity and interacts with the other proteins. The overexpression of either GDC-H protein or GDC-L protein in Arabidopsis thaliana resulted in increases in $\mathrm{CO}_{2}$ assimilation rate and plant biomass (Timm et al. 2012, 2015, 2016). Additionally, the overexpression of GDC-H contributed to greater plant growth in tobacco (Nicotiana tabacum) in both a controlled environment and under field conditions (Lopez-Calcagno et al. 2018). Although the underlying mechanism responsible for these effects has not been fully elucidated, it has been proposed that the Calvin-Benson cycle is stimulated by the increase in GDC activity, resulting in a decrease in the steadystate levels of photorespiratory metabolites.

\section{Improving Thermotolerance of Rubisco Activase}

The Rubisco catalytic sites must be activated to fix $\mathrm{CO}_{2}$ (Fig. 2). This requires the carbamylation of a lysine residue at the Rubisco catalytic site, allowing the binding of $\mathrm{Mg}^{2+}$ and ribulose-1,5-bisphosphate (RuBP). Rubisco activase facilitates carbamylation and the maintenance of Rubisco activity by removing inhibitors such as tight-binding sugar phosphates from the Rubisco catalytic sites in an ATP-dependent manner (Spreitzer and Salvucci 2002; Portis Jr 2003; Parry et al. 2008).

In many plant species, the Rubisco activation state decreases at high temperatures (Crafts-Brandner and Salvucci 2000; Salvucci and Crafts-Brandner 2004a; Yamori et al. 2006b, 2014; Yamori and von Caemmerer 2009). Rubisco deactivation at high temperature could have occurred because Rubisco activase is insufficiently active to keep pace with the faster rates of Rubisco inactivation at high temperature due to its thermolability (Salvucci and Crafts-Brandner 2004b). A decrease in Rubisco activase content resulted in decreases in photosynthetic rate at high temperature when using mutants/transgenic plants in Arabidopsis (Salvucci et al. 2006), rice (Yamori et al. 2012), and tobacco (Yamori and von Caemmerer 2009). Also, the overexpression of Rubisco activase from maize into rice stimulated the Rubisco activation state and photosynthetic rate at high temperature (Yamori et al. 2012). Moreover, transgenic Arabidopsis expressing thermotolerant Rubisco activase isoforms generated by either gene shuffling technology (Kurek et al. 2007) or chimeric Rubisco activase constructs (Kumar et al. 2009) improved photosynthesis, biomass production, and seed yield. In addition, the introduction of Rubisco activase from cotton into a cool-season species such as Camelina resulted in improvement in the thermotolerance of photosynthesis (Carmo-Silva and Salvucci 2012). This is also supported by a recent report stating that genes encoding thermostable Rubisco 
activase from a wild relative (Oryza australiensis) were overexpressed in domesticated rice $(O$. sativa $)$, leading to an improvement in plant growth and seed yield in rice under heat stress (Scafaro et al. 2018). Taken together, Rubisco activase activity would constitute a major limiting factor for photosynthesis under high temperature and engineering Rubisco activase would be an efficient way to improve crop yield under high temperatures. The structure of Rubisco activase has already been determined, providing insight into its interactions with Rubisco (Stotz et al. 2011) and its counterpart CbbX in red algae (Mueller-Cajar et al. 2011). This structural information coupled with the knowledge of regulation in Rubisco activase will help to improve its thermostability and catalytic properties.

\section{Increasing $\mathrm{CO}_{2}$ Concentration Around Rubisco}

Photosynthesis in $\mathrm{C}_{3}$ plants is limited by the large drawdown in $\mathrm{CO}_{2}$ concentrations from the atmosphere to the Rubisco catalytic sites in chloroplasts. The $\mathrm{CO}_{2}$ diffusion conductance responsible for this drawdown is attributed to the stomatal pores and the paths across the mesophyll from the cell surface to the Rubisco catalytic sites in chloroplasts (Evans et al. 2009). Increasing $\mathrm{CO}_{2}$ concentration in chloroplasts and thereby minimizing photorespiration is therefore a promising target in terms of increasing photosynthetic rate in crops. $\mathrm{CO}_{2}$ diffusion to the chloroplast can be influenced by modifying conductance through the stomata (stomatal conductance) to the intercellular air space, either by increasing stomatal density (Tanaka et al. 2013) or by preventing stomatal closure (Kusumi et al. 2012; Yamori et al. 2020). Both approaches would result in increases in photosynthetic rate at the cost of higher transpiration rates and lower water-use efficiency.

An alternative approach addresses the other major diffusion conductance route for $\mathrm{CO}_{2}$ from the intercellular air space into the mesophyll cell chloroplasts (mesophyll conductance). In contrast to modifying stomatal conductance, increasing mesophyll conductance does not negatively affect water-use efficiency. The resistance of the cell wall (25-50\%) and chloroplast (24-76\%) accounts for most of the total resistance (Evans et al. 2009), meaning that $\mathrm{CO}_{2}$ diffusion can potentially be improved by modifying plants so that they have smaller mesophyll cells (i.e., a higher surface area of the chloroplasts is exposed to intercellular air spaces, $\mathrm{Sc}$ ) with thinner cell walls (Terashima et al. 2011). The second important component of mesophyll conductance involves $\mathrm{CO}_{2}$ diffusion through the plasma and chloroplast membranes (Evans et al. 2009), and several approaches are being developed to increase $\mathrm{CO}_{2}$ concentration in chloroplasts in $\mathrm{C}_{3}$ plants by increasing membrane permeability for $\mathrm{CO}_{2}$. Aquaporins that are permeable to $\mathrm{CO}_{2}$ are proteins that assist $\mathrm{CO}_{2}$ diffusion through the membranes by providing pores through which $\mathrm{CO}_{2}$ can be channeled (Kaldenhoff 2012). It has been shown that disruption to the aquaporin AtPIP1;2 gene limits $\mathrm{CO}_{2}$ transport across the membrane (Heckwolf et al. 2011), while the overexpression of different aquaporin genes results in increased $g_{\mathrm{m}}$ (Hanba et al. 2004; Flexas et al. 2006). Furthermore, it has been shown that the expression 
of an aquaporin in $A$. thaliana stimulates $\mathrm{CO}_{2}$ flux through a mesophyll membrane (Uehlein et al. 2012).

Once $\mathrm{CO}_{2}$ is transferred to the cytosol, it is partially converted into $\mathrm{HCO}_{3}{ }^{-}$to facilitate its diffusion into the chloroplast, and the $\mathrm{HCO}_{3}{ }^{-}$is then dehydrated back to $\mathrm{CO}_{2}$ by carbonic anhydrase to maintain a high $\mathrm{CO}_{2}$ flux through the chloroplast membrane. Thus, carbonic anhydrase plays a role in facilitating the diffusion of $\mathrm{CO}_{2}$ in the chloroplast stroma by interconverting between $\mathrm{CO}_{2}$ and $\mathrm{HCO}_{3}^{-}$(Evans et al. 2009). It has been suggested that the amount of carbonic anhydrase found in plants somewhat limits conductance in the stroma of $\mathrm{C}_{3}$ crops, and thus there would be a possibility to improve this aspect by molecular engineering (Tholen and Zhu 2011).

A substantial increase in the $\mathrm{CO}_{2}$ concentration around Rubisco to enhance photosynthesis and water-use efficiency has been expected as the result of the installation of a carbon concentrating mechanism (CCM) in $\mathrm{C}_{3}$ plants (Fig. 4). Cyanobacteria have evolved a CCM in which Rubisco is encapsulated in a cellular compartment known as a carboxysome (Price et al. 2011). In carboxysomes, $\mathrm{CO}_{2}$ concentration is enriched by up to 1000 -fold, thus significantly decreasing the photorespiration rate.

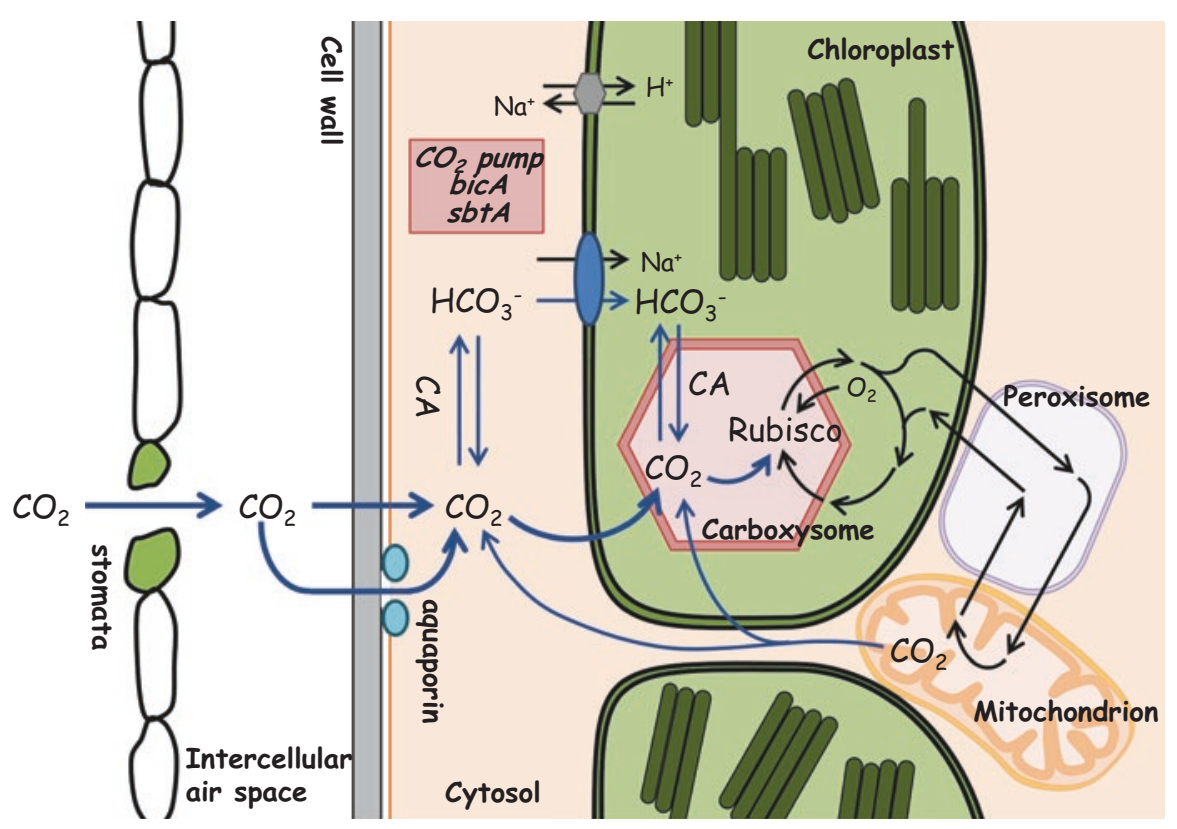

Fig. 4 Schematic diagram of mechanisms for concentrating $\mathrm{CO}_{2}$ around Rubisco. The diagram shows $\mathrm{CO}_{2}$ transfers from the outside to the intercellular air space through the stomatal pore and the $\mathrm{CO}_{2}$ diffuses through the cell wall and plasma membrane into the cytosol. Aquaporins assist the $\mathrm{CO}_{2}$ diffusion into the cytosol of the mesophyll cell through the membranes by providing pores through which $\mathrm{CO}_{2}$ can be channeled. Introducing a cyanobacterial $\mathrm{HCO}_{3}{ }^{-}$transporter (e.g., bic $\mathrm{A}$ and $s b t A$ ) into the chloroplast envelope could improve $\mathrm{CO}_{2}$ transport. The introduction of a Rubisco- and carbonic-anhydrase-containing compartment, such as the carboxysome, could further increase the $\mathrm{CO}_{2}$ concentration around Rubisco, resulting in minimization of the photorespiration rate. (The figure is adapted from Price et al. (2011) and Yamori et al. (2016b)) 
To incorporate $\mathrm{CCM}$ from cyanobacteria into $\mathrm{C}_{3}$ plants, the following distinct features need to be addressed: (1) $\mathrm{CO}_{2}$ and $\mathrm{HCO}_{3}{ }^{-}$transport mechanism and (2) functional carboxysome assembly. Incorporating cyanobacterial $\mathrm{HCO}_{3}{ }^{-}$transporters into the chloroplast envelope of $\mathrm{C}_{3}$ plants would provide a parallel route for inorganic carbon to enter the chloroplast, in addition to the diffusion of dissolved $\mathrm{CO}_{2}$ (Price et al. 2011, 2013). To date, five different inorganic carbon transport mechanisms have been identified in cyanobacteria (Price et al. 2011, 2013). A previous study showed that overexpressing the $i c t B$ gene, an $\mathrm{HCO}_{3}{ }^{-}$transporter in cyanobacteria, in A. thaliana and N. tabacum plants contributed more to increases in photosynthesis and water-use efficiency than in the wild type (Lieman-Hurwitz et al. 2003). Furthermore, the overexpression of the $i c t B$ gene in soybeans led to increases in mesophyll conductance, photosynthesis, and plant productivity in both ambient and elevated $\mathrm{CO}_{2}$ environments under both greenhouse and field conditions (Hay et al. 2017). It is now considered that a fully functional $\mathrm{CCM}$ in $\mathrm{C}_{3}$ plants would require the introduction of $\mathrm{HCO}_{3}{ }^{-}$transporters, adjustments in the expression of chloroplast carbonic anhydrase to allow $\mathrm{HCO}_{3}{ }^{-}$accumulation, and the establishment of a Rubisco- and carbonic-anhydrase-containing compartment, such as a carboxysome (Price et al. 2011, 2013). Recently, well-assembled carboxysome structures were successfully expressed in plants (Long et al. 2018). Incorporation of cyanobacterial Rubisco large and small subunit genes along with genes for carboxysome structural proteins could improve Rubisco catalytic properties, but decrease total Rubisco content, resulting in lower photosynthetic rates and growth than in tobacco wild-type (Long et al. 2018). Since the incorporation of CCM into crops has been expected to improve crop yields, efforts toward transplantation are under way.

$\mathrm{C}_{4}$ plants evolved CCM in two types of photosynthetic cells, where $\mathrm{CO}_{2}$ is initially fixed in the mesophyll cells by the enzyme phosphoenolpyruvate carboxylase (PEPC) to produce $\mathrm{a}_{4}$ acid. The organic acid diffuses to the bundle-sheath cells, where it is decarboxylated, resulting in significantly increased $\mathrm{CO}_{2}$ concentrations around Rubisco. Currently, considerable efforts are under way to incorporate the features of the complex $\mathrm{C}_{4}$ pathway into $\mathrm{C}_{3}$ crops such as rice (Covshoff and Hibberd 2012; von Caemmerer et al. 2012). Challenges associated with this approach include morphological adjustments, such as the establishment of a Kranz(-like) anatomy, as well as the introduction of $\mathrm{C}_{4}$ biochemistry into $\mathrm{C}_{3}$ leaves. The benefits of the introduction of the $\mathrm{C}_{4}$ photosynthetic pathway would include higher yield as well as improved nitrogen-use efficiency and water-use efficiency.

\section{Enhancing Activity of Calvin-Benson-Cycle Enzymes}

The Calvin-Benson cycle uses ATP and NADPH from photosynthetic electron transport to fix $\mathrm{CO}_{2}$ in carbon skeletons that are mainly used for sucrose and starch production (Fig. 2). The Calvin-Benson cycle also supplies intermediates to many other pathways in the chloroplast, including the shikimate pathway for the 
biosynthesis of amino acids, lignin, isoprenoid, and precursors for nucleotide metabolism and cell wall synthesis. This cycle comprises 11 different enzymes, catalyzes 13 reactions, and is initiated by Rubisco (Raines 2003). Four of the 11 enzymes are regulated by thioredoxins: glyceraldehyde 3-phosphate dehydrogenase (GAPDH), fructose 1,6-bisphosphatase (FBPase), sedoheptulose-1,7-bisphosphatase (SBPase), and phosphoribulokinase (PRK). Two of the 11 enzymes catalyze reversible reactions: aldolase and transketolase.

Previous studies have demonstrated that moderate reductions in Calvin-Bensoncycle enzymes such as SBPase and fructose 1,6-bisphosphate aldolase (FBPA) induce significant decreases in photosynthetic rate and plant growth, indicating that these enzymes would limit photosynthesis (Ding et al. 2016; Haake et al. 1998, 1999; Harrison et al. 1998, 2001; Lawson et al. 2006; Ölcer et al. 2001; Raines 2003; Raines and Paul 2006; Raines et al. 1999; Hatano-Iwasaki and Ogawa 2012). Furthermore, the disruption of the chloroplastic FBPase was also shown to negatively affect photosynthetic rate (Kossmann et al. 1994; Rojas-González et al. 2015; Sahrawy et al. 2004). These results strongly suggest that photosynthetic $\mathrm{CO}_{2}$ fixation could be improved by increasing the activity of individual Calvin-Bensoncycle enzymes. Evidence supporting this hypothesis was provided by transgenic tobacco plants overexpressing SBPase (Lefebvre et al. 2005; Tamoi et al. 2006), FBPase (Tamoi et al. 2006), the cyanobacterial bifunctional SBPase/FBPase (Miyagawa et al. 2001), or FBPA (Uematsu et al. 2012). These single manipulations resulted in increases in photosynthetic rate and plant growth. Recently, SBPase has been receiving a lot of attention, and its role in determining carbon flux in the Calvin-Benson cycle under natural environmental conditions has been revealed. Transgenic tobacco plants overexpressing SBPase from A. thaliana exhibited an enhanced photosynthetic rate and biomass production when grown under free-air $\mathrm{CO}_{2}$ enrichment (FACE) conditions at a $\mathrm{CO}_{2}$ concentration of $585 \mu \mathrm{mol} / \mathrm{mol}$ (Rosenthal et al. 2011). Moreover, the expression of cyanobacterial bifunctional FBPase/SBPase increases photosynthetic rate in soybeans grown under field conditions and prevents yield losses under high- $\mathrm{CO}_{2}$ and high-temperature conditions (Köhler et al. 2016). In addition, transgenic lines with increased SBPase exhibited improvement of leaf photosynthesis, total biomass, and seed yield in wheat under greenhouse conditions (Driever et al. 2017). Taken together, the manipulation of SBPase could increase photosynthetic capacity and could be an efficient way to improve photosynthetic rate and crop yield, especially in a future high- $\mathrm{CO}_{2}$ world.

\section{Enhancing Electron Transport Rate in Thylakoid Membranes}

ATP and NADPH generated during photosynthetic electron transport in thylakoid membranes are used to power photosynthetic carbon reduction. In a future high$\mathrm{CO}_{2}$ world, $\mathrm{CO}_{2}$ assimilation rate would be limited by the RuBP regeneration rate in the Calvin-Benson cycle (Farquhar et al. 1980), which in turn will be limited by 
chloroplast electron transport capacity (Yamori et al. 2011). The cytochrome $b_{6} / f$ complex has a unique role in chloroplast electron transport (Fig. 5) as it can act in both linear electron transport (production of ATP and NADPH) and cyclic electron transport (ATP generation only). There is a strong linear relationship between chloroplast electron transport rate and cytochrome $\mathrm{b}_{6} / \mathrm{f}$ complex content at any leaf temperature (Yamori et al. 2011). Thus, this could be a suitable target for genetic manipulation to improve photosynthesis and thus plant yield.

Previous experiments with antisense lines have shown that even a moderate decrease in the amounts of chloroplastic ferredoxin NADP $(\mathrm{H})$ oxidoreductase (FNR), which catalyzes the terminal reaction of the photosynthetic electron transport chain by transferring electrons from reduced ferredoxin to $\mathrm{NADP}^{+}$, has a negative impact on photosynthetic rate under both low and high light conditions (Hajirezaei et al. 2002). However, the overexpression of FNR (Rodriguez et al.

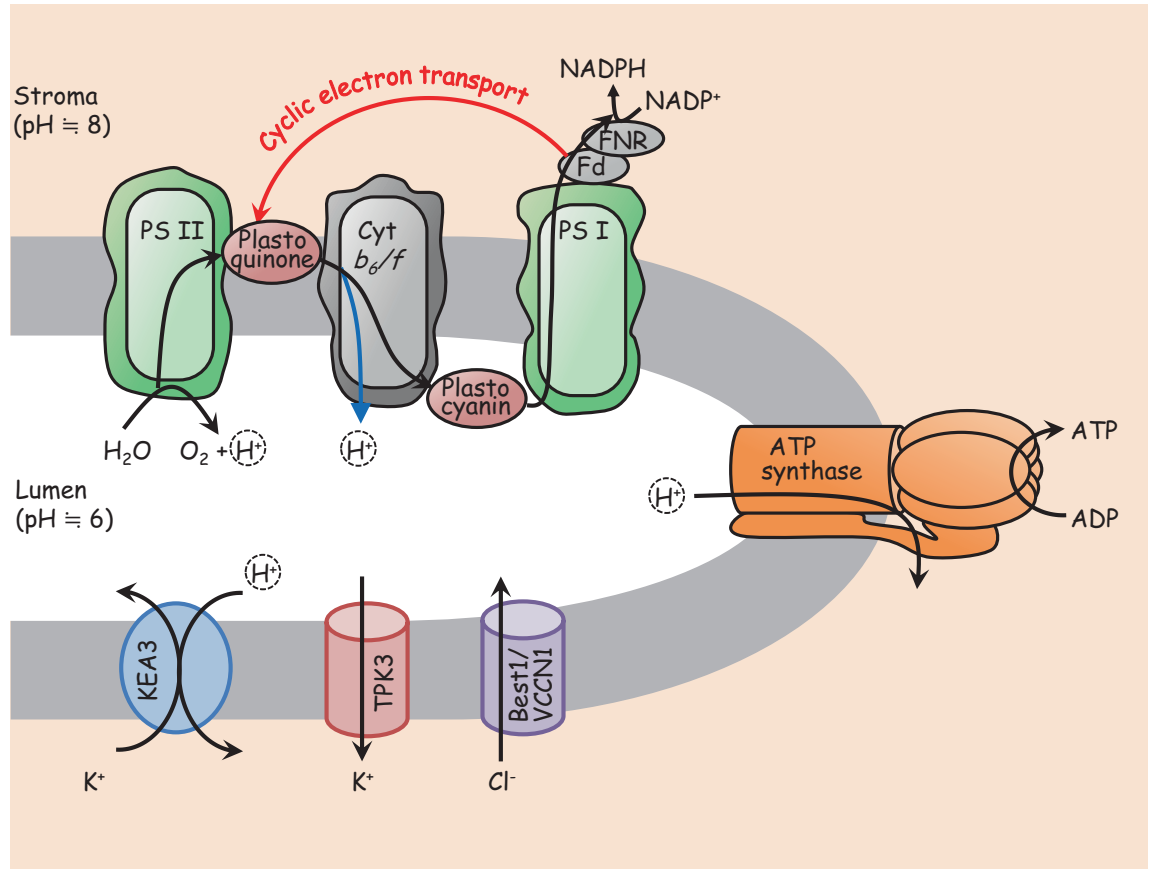

Fig. 5 Schematic diagram of electron transport in thylakoid membranes. Electron transport, driven by the excitation of photosystem I (PS I) and photosystem II (PS II), results in the reduction of $\mathrm{NADP}^{+}$to NADPH and the accumulation of protons in the thylakoid lumen. The resulting proton motive force $(p m f)$, which constitutes $\Delta \mathrm{pH}$ across the thylakoid membrane as well as membrane potential $(\Delta \psi)$, is used to produce ATP through ATP synthase. Linear electron transport generates both ATP and NADPH, whereas cyclic electron transport produces ATP without producing NADPH. Several ion channels, such as the thylakoid $\mathrm{K}^{+}$channel TPK3, $\mathrm{K}^{+}$efflux antiporters $\mathrm{KEA}$, and $\mathrm{Cl}^{-}$channel Best1/VCCN1, would adjust $\Delta \psi$ and $\Delta \mathrm{pH}$ and function to fine-tune pmf and thus electron transport via $\mathrm{pH}$-dependent NPQ. PS II: photosystem II, Cyt $\mathrm{b}_{6} \mathrm{f}$, cytochrome $\mathrm{b}_{6} / \mathrm{f}$ complex, PS I: photosystem I, Fd: ferredoxin. FNR: ferredoxin-NADP+ ${ }^{+}$reductase 
2007) or ferredoxin (Yamamoto et al. 2006) did not increase photosynthesis or plant growth in tobacco, irrespective of growth light conditions. Electron transfer between the cytochrome $b_{6} / f$ complex and photosystem $I$ is mediated by plastocyanin in higher plants, whereas, in many algae, it is mediated by cytochrome $c 6$. Variations in plastocyanin levels have been reported to coincide with variations in photosynthetic electron transport activity (Burkey 1994; Burkey et al. 1996; Schöttler et al. 2004), leading to the conclusion that plastocyanin pool size could limit photosynthetic electron transport. It has been reported that the introduction of a parallel electron carrier between the cytochrome $\mathrm{b}_{6} / \mathrm{f}$ complex and photosystem I through the expression of an algal cytochrome $c 6$ gene in A. thaliana improved electron transport rate, leading to improved plant growth (Chida et al. 2007). An analysis of knockout plants for two homologous plastocyanin isoforms (PETE1 and PETE2) in A. thaliana showed that plastocyanin content can be significantly decreased with no apparent changes in photosynthetic rate, suggesting that the concentration of plastocyanin does not limit photosynthetic electron transport rate (Pesaresi et al. 2009). However, the overexpression of either PETE1 or PETE2 results in an increase in biomass production (Pesaresi et al. 2009). Thus, there is still a discrepancy between the experimental knockout data and the overexpression lines.

It was also shown in antisense studies that decreasing Rieske FeS protein content resulted in a decrease in cytochrome $b_{6} / f$ complex level, leading to a decrease in photosynthetic electron transport, plant biomass, and seed yield in tobacco and rice (Price et al. 1998; Yamori et al. 2016a). These findings identified the cytochrome $\mathrm{b}_{6} / \mathrm{f}$ complex as a limiting step in electron transport and would suggest that the overexpression of Rieske FeS protein could be a suitable target for increasing photosynthesis and yield. This has been proven by recent work showing that the overexpression of Rieske FeS protein had a substantial and significant impact on electron transport, plant biomass, and seed yield in Arabidopsis plants (Simkin et al. 2017).

Other reports have documented an enhancement in plant biomass realized by the genetic manipulation of photosynthetic electron transport. In plant cells, NADP is mainly located in the chloroplast, where $\mathrm{NADP}^{+}$functions as the final electron acceptor of the photosynthetic electron transport chain (Wigge et al. 1993). NAD kinase regulates the $\mathrm{NAD}(\mathrm{H}) / \mathrm{NADP}(\mathrm{H})$ balance through its catalysis of NAD phosphorylation in the presence of ATP (Kawai and Murata 2008). In A. thaliana, one of the NADK isoforms localized in the chloroplast (NADK2; Chai et al. 2005) catalyzes a key step in the regulation of NAD/NADP ratio (Kawai and Murata 2008). The overexpression of chloroplastic NADK2 from Arabidopsis plants into rice succeeded in enhancing electron transport and $\mathrm{CO}_{2}$ assimilation rates (Takahara et al. 2010).

In situations in which the electron transport rate is limited by the amount of available light that can be absorbed by the plant, increased light harvesting might enhance photosynthetic rate and plant productivity. Land plants use chlorophyll $a$ and $b$, which absorb light at wavelengths of $400-700 \mathrm{~nm}$. Chlorophyll $d$, which is used by Acaryochloris (Miyashita et al. 1996), and chlorophyll $f$, which was discovered in the cyanobacterial communities of stromatolites (Chen et al. 2010), have red-shifted absorption spectra that enable their host organisms to perform oxygenic 
photosynthesis at the much longer wavelengths of 700-750 nm, which are inaccessible to other organisms. Introducing these chlorophylls into higher plants to supplement or replace the existing chlorophylls could potentially increase the amount of usable photon flux by up to 19\% (Chen and Blankenship 2011). The up-regulation of Arabidopsis chlorophyllide $a$ oxygenase (CAO), involved in chlorophyll $b$ biosynthesis, in tobacco has been shown to increase electron transport rate, $\mathrm{CO}_{2}$ assimilation, and plant biomass (Biswal et al. 2012). In addition, plants with a mutation in TAP38, an enzyme involved in the dephosphorylation of the light harvesting complex of photosystem II, exhibited an increased photosynthetic electron flow, leading to improved plant growth under low-light conditions (Pribil et al. 2010). In the same manner, facilitation of the chloroplast accumulation response, which shows that chloroplasts accumulate along periclinal cell walls at low light, led to improved leaf photosynthesis and plant biomass production in A. thaliana (Gotoh et al. 2018). Since the photosynthetic electron transport chain provides energy and reducing equivalents for the reduction of fixed $\mathrm{CO}_{2}$ to carbohydrates in the CalvinBenson cycle as well as for nitrogen assimilation and other processes, the genetic manipulation of photosynthetic electron transport could be a candidate for improving the entire photosynthetic system, and thus plant yield.

\section{Improving Photosynthetic Performance Under Fluctuating Light in Natural Environments}

Research into finding ways to increase crop yield has focused on improving steadystate photosynthesis. However, leaves in natural plant canopies experience a highly variable light environment over the course of a day because of changes in cloud cover and overshadowing canopy cover (Fig. 6; Yamori 2016). By contrast, transgenic plants have not yet been used to clarify the limiting step of non-steady-state photosynthesis, and thus few studies address the improvement of non-steady-state photosynthesis. When light intensity is increased suddenly after a prolonged period of low light or darkness, photosynthetic rate increases gradually over several minutes and approaches a steady state (Pearcy 1990; Yamori 2016). This phenomenon has been termed "photosynthetic induction," and it is typically divided into three limiting phases: (1) electron transport systems; (2) activation of Calvin-cycle enzymes, especially Rubisco; and (3) $\mathrm{CO}_{2}$ diffusion into the chloroplast (Fig. 6). The first of these three phases is often completed within 1-2 min of increases in irradiance, the second requires 5-10 min, and the third could take 10-30 min to reach a steady-state (Pearcy 1990). The slow induction results in a time lag between the changes in irradiance and those in the photosynthetic rate. This delay may cause damage to the photosynthetic apparatus and eventually decrease plant productivity if excess energy accumulates during repeated fluctuations in light intensity (Murchie and Niyogi 2011; Tikkanen et al. 2012; Yamori 2016; Yamori et al. 2016c). Daily photosynthetic rates under fluctuating light conditions can be up to 20-35\% lower 


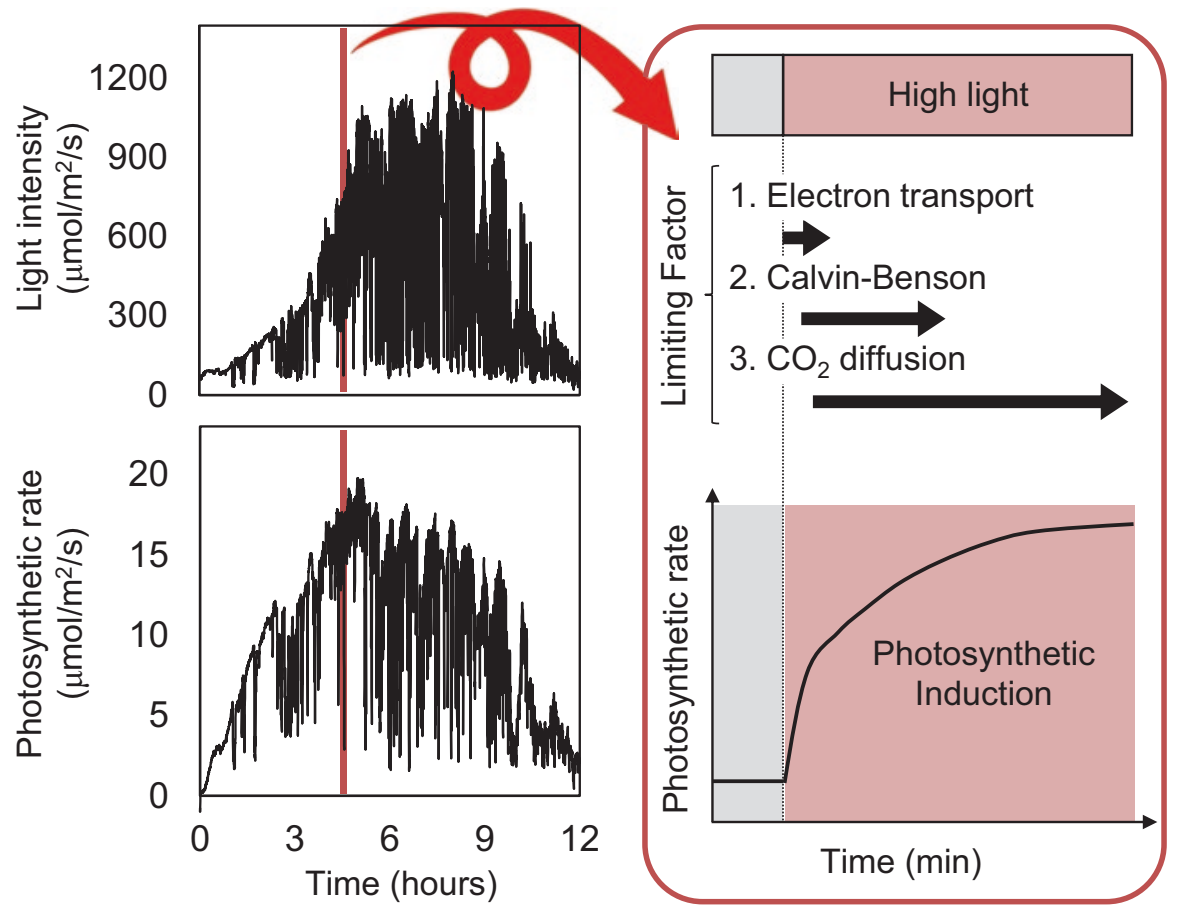

Fig. 6 Representative responses of photosynthetic rate under field light conditions. The natural light fluctuations were mimicked in portable photosynthesis systems (LI-6400XT), and the photosynthetic rates at a $\mathrm{CO}_{2}$ concentration of $400 \mu \mathrm{mol} / \mathrm{mol}$ were measured under these light conditions. Three arrows in the right figure indicate major biochemical processes limiting photosynthetic induction with different time courses

than the optimal photosynthetic rates under constant light (Naumburg and Ellsworth 2002; Taylor and Long 2017). Therefore, characterization of the mechanisms that regulate photosynthetic responses to fluctuating light intensities may lead to improved photosynthetic induction and crop yield under natural conditions (Tanaka et al. 2019). The following section summarizes the various genetic engineering approaches that can be used to enhance photosynthesis under fluctuating light conditions (Fig. 7).

\subsection{Electron Transport}

Photosynthetic electron transport systems consist of linear and cyclic electron transport around photosystem I (Fig. 7). Linear electron transport generates both ATP and NADPH for a Calvin-Benson cycle, photorespiration, and other metabolisms. On the other hand, cyclic electron transport produces ATP without producing $\mathrm{NADPH}$ to balance the ATP/NADPH production ratio and is now considered to be 

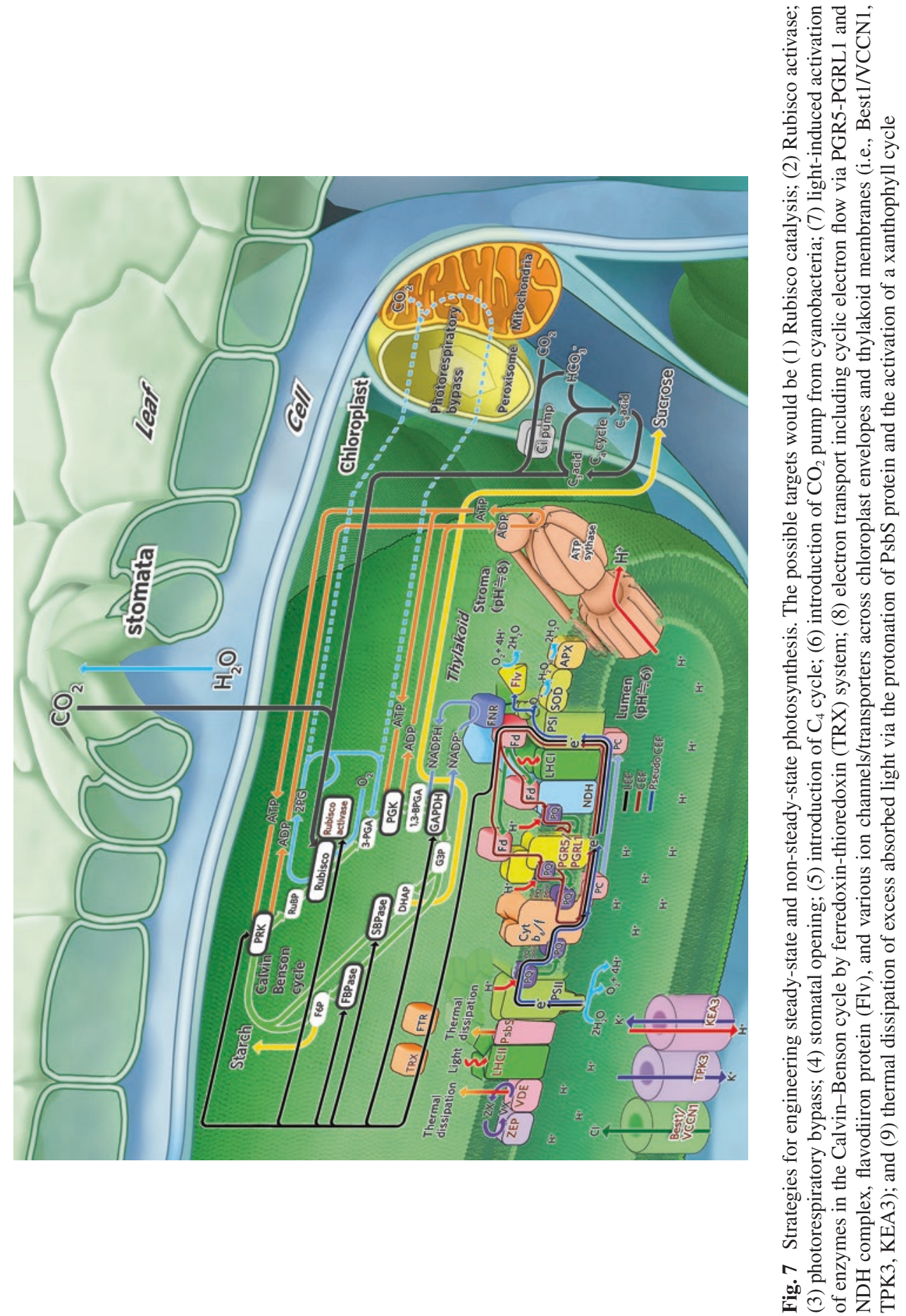
essential in providing protection from photodamage via the thermal dissipation of excess absorbed light (NPQ, non-photochemical quenching) (Yamori and Shikanai 2016). There are two cyclic electron flows around photosystem I: the main pathway depends on PGR5/PGRL1 proteins and the minor pathway depends on a chloroplast NADH dehydrogenase-like (NDH) complex. It has been shown in rice that PGR5/ PGRL1-dependent cyclic electron transport is a key regulator of rapid photosynthetic responses to high light intensity under fluctuating light, and that both PGR5/ PGRL1-dependent and NDH-dependent cyclic electron transport have physiological roles for photoprotection in sustaining photosynthesis and plant growth in rice under repeated light fluctuations (Yamori et al. 2016c). In cyanobacteria, pseudocyclic electron transport by flavodiiron protein $(F l v)$ mediates the photoreduction of $\mathrm{O}_{2}$ to $\mathrm{H}_{2} \mathrm{O}$ and is essential for photosystem-I photoprotection in fluctuating light (Allahverdiyeva et al. 2013). Recent work indicated that the introduction of the Flv gene from moss (Physcomitrella patens) into Arabidopsis and rice led to the enhancement of cyclic electron transport, resulting in successful improvement of the resistance of photosynthetic machinery under fluctuating light conditions (Fig. 7; Yamamoto et al. 2016; Wada et al. 2018).

NPQ can be activated and relaxed within minutes and is a highly regulatory process involving multiple factors, such as the protonation of PsbS protein and the activation of a xanthophyll cycle that converts the pigment violaxanthin (V) to antheraxanthin (A) and zeaxanthin (Z) (for a review, see Yamori and Shikanai 2016). In tobacco, the simultaneous overexpression of PsbS, violaxanthin de-epoxidase, and zeaxanthin epoxidase increases the rate of NPQ relaxation, which subsequently increases growth under fluctuating light in field conditions (Fig. 7; Kromdijk et al. 2016). Thus, plant productivity and crop yield appear to be highly dependent on NPQ under fluctuating light conditions in nature.

It has been reported that ion channels/transporters across chloroplast envelopes and thylakoid membranes play fundamental roles in the regulation of photosynthetic electron transport (Figs. 5 and 7; Finazzi et al. 2015). Photosynthetic electron transport is coupled with proton translocation across the thylakoid membrane, resulting in the formation of transmembrane $\mathrm{H}^{+}$concentration $(\Delta \mathrm{pH})$ and electrical potential $(\Delta \Psi)$ gradients. Although both $\Delta \mathrm{pH}$ and $\Delta \psi$ contribute to ATP synthesis as a proton motive force ( $p m f$ ), only the $\Delta \mathrm{pH}$ component can activate the PsbS- and xanthophyll-cycle-dependent NPQ while down-regulating electron transport during the plastoquinol oxidation step at the cytochrome $\mathrm{b}_{6} / \mathrm{f}$ complex (photosynthetic control, Kramer et al. 2003; Yamori and Shikanai 2016). Recent evidence suggests that several ion channels, such as the thylakoid $\mathrm{K}^{+}$channel TPK3, $\mathrm{K}^{+}$efflux antiporter $\mathrm{KEA} 3$, and $\mathrm{Cl}^{-}$channel Best1/VCCN1, adjust electron transport and functions in photoprotective mechanisms (Figs. 5 and 7; Carraretto et al. 2013; Kunz et al. 2014; Duan et al. 2016; Herdean et al. 2016). The knockout of Best1/VCCN1, which leads to an influx of $\mathrm{Cl}^{-}$into the lumen, resulted in disturbance of the pmf components, resulting in a decreased rate of NPQ induction (Duan et al. 2016; Herdean et al. 2016). These data suggest that a $\mathrm{Cl}^{-}$influx into the lumen would fine-tune $\mathrm{pmf}$ and allow the plant to adjust photosynthesis to variable light. On the other hand, TPK3 effluxes $\mathrm{K}^{+}$ 
from the thylakoid lumen to the stroma and partially dissipates $\Delta \Psi$ to allow more $\mathrm{H}^{+}$to enter the lumen and thus enables a significant $\Delta \mathrm{pH}$ to be formed, thus balancing photoprotection and photochemical efficiency (Carraretto et al. 2013). Moreover, KEA3 effluxes $\mathrm{H}^{+}$with the counter influx of $\mathrm{K}^{+}$, exchanging $\Delta \psi$ for $\Delta \mathrm{pH}$, which is critical for photosynthetic acclimation after transitions from high to low light (Kunz et al. 2014; Armbruster et al. 2014). The activity of KEA3 accelerates the down-regulation of $\mathrm{pH}$-dependent NPQ after transitions to low light, leading to the faster recovery of high photosystem II quantum efficiency and increased $\mathrm{CO}_{2}$ assimilation. The overexpression of KEA3 accelerates the relaxation of photoprotective energy-dependent quenching after transitions from high to low light in Arabidopsis and tobacco (Armbruster et al. 2016). Thus, the KEA3 function is critical in terms of realizing high photosynthetic efficiency under fluctuating light. Taken together, these findings underscore the potential for accelerating NPQ relaxation once light intensity is decreased so as not to decrease the efficiency of light energy use under lightlimiting conditions in improving photosynthetic efficiency under fluctuating light in field conditions (Fig. 7).

\subsection{Activation of Calvin-Cycle Enzymes, Especially Rubisco}

Rubisco must be activated by Rubisco activase to catalyze $\mathrm{CO}_{2}$ assimilation in the Calvin-Benson cycle (Fig. 7). A positive relationship has been observed between Rubisco activase content and the speed of the photosynthetic induction response in A. thaliana (Mott et al. 1997), tobacco (Hammond et al. 1998; Yamori and von Caemmerer 2009), and rice (Masumoto et al. 2012; Yamori et al. 2012). Thus, it is considered that the Rubisco activation state could be a limiting factor for the induction response to a sudden increase in light intensity. In most species, Rubisco activase is present in two isoforms: redox-regulated $\alpha$-isoform and redox-insensitive $\beta$-isoform (Portis Jr 2003). In transgenic Arabidopsis plants containing only the $\beta$-isoform, photosynthetic induction after a transition from low to high light was faster than in the wild type, as Rubisco activase activity was constitutively high and independent of irradiance (Carmo-Silva and Salvucci 2013; Kaiser et al. 2016). Furthermore, the overexpression of $\beta$-isoform from maize in rice led to an improvement in photosynthetic induction via the rapid regulation of the Rubisco activation state by Rubisco activase following an increase in light intensity and/or the maintenance of a high Rubisco activation state under low light (Yamori et al. 2012). Taken together, modifying the concentration of Rubisco activase and its composition could be used to improve photosynthetic performance and plant growth under fluctuating light conditions.

Thioredoxins are ubiquitous enzymes in chloroplasts, and the thioredoxin systems are responsible for the light-induced activation of enzymes in the CalvinBenson cycle, including GAPDH, FBPase, SBPase, and PRK (Thormählen et al. 2017); ATP synthesis (Hisabori et al. 2013); malate-oxaloacetate shuttle 
(Miginiac-Maslow et al. 2000); and starch metabolism (Thormählen et al. 2013). There are two plastid thioredoxins systems: (1) the ferredoxin-thioredoxin system, which consists of ferredoxin-thioredoxin reductase (FTR) and multiple thioredoxins, and (2) the NADPH-dependent thioredoxin reductase (NTRC) system, which contains a complete thioredoxin system (Fig. 7). Recent reports focusing on the overexpression of chloroplast thioredoxin components in plants support the concept of the high impact of thioredoxins on plant fitness. Transgenic tobacco lines overexpressing thioredoxin $f$, one of the thioredoxin families, showed a large increase in plant biomass and starch content, which was further stimulated by an increase in light intensity (Sanz-Barrio et al. 2013). The overexpression of the endogenous NTRC gene in Arabidopsis also increased plant growth under moderate light intensity (Toivola et al. 2013). Furthermore, a recent study showed that both ferredoxin-dependent thioredoxin $m$, one of the thioredoxin families, and NADPH-dependent NTRC are indispensable for photosynthetic acclimation in fluctuating light intensities (Nikkanen et al. 2016; Thormählen et al. 2017). Thus, it is highly possible that thioredoxin-mediated redox regulation allows the activation state of these enzymes to be modulated in response to fluctuating light in field conditions.

\section{3 $\mathrm{CO}_{2}$ Diffusion into the Chloroplast}

The diffusion of $\mathrm{CO}_{2}$ to the Rubisco catalytic sites in the chloroplast is mediated by both stomatal and mesophyll conductance (Fig. 7). Under naturally fluctuating environmental conditions, stomatal responses are much slower than photosynthetic responses. Manipulating stomatal conductance so that it responds more quickly to irradiance could greatly enhance photosynthesis and water-use efficiency in fluctuating irradiance (Lawson and Blatt 2014; Vialet-Chabrand et al. 2017). Removal of the stomatal limitation could increase photosynthetic induction in aba2-1 Arabidopsis mutant, which impaired ABA synthesis and thus showed constitutively high stomatal conductance (Kaiser et al. 2016). Moreover, SLACl-deficient rice mutant, which knocked out an anion channel protein in the plasma membrane of stomatal guard cells, constitutively opened stomata and contributed to higher photosynthetic rates more than the wild type in naturally fluctuating light (Yamori et al. 2020). Papanatsiou et al. (2019) induced a synthetic, light-gated $\mathrm{K}^{+}$channel in guard cells in Arabidopsis and succeeded in facilitating stomatal opening under light exposure and closing after irradiation, leading to greater plant growth in fluctuating light. Furthermore, several Arabidopsis mutants with stay-open stomata and the PATROLI (proton ATPase translocation control 1) overexpression Arabidopsis line with faster stomatal opening responses exhibited higher photosynthetic rates and plant growth in fluctuating light than the wild type, whereas those lines showed similar photosynthetic rates and plant growth in constant light (Shimadzu et al. 2019; Kimura et al. 2020). Taken together, 
enhancing stomatal conductance could result in better use of plant photosynthetic capacity in naturally fluctuating light.

In addition to stomatal conductance, mesophyll conductance could place a large diffusional limitation on photosynthesis. The extent to which mesophyll conductance limits photosynthesis under fluctuating light is largely unknown, although it has been reported that mesophyll conductance could impose a major limitation to photosynthesis during the steady state. Mesophyll conductance can vary within minutes, and is affected by changes in irradiance, $\mathrm{CO}_{2}$, and temperature (Flexas et al. 2007, 2008, 2012; Tazoe et al. 2011; Tholen et al. 2008; Yamori et al. 2006a), making it a potentially important process. Recently, we succeeded to characterize induction both of mesophyll conductance and stomatal conductance after a step change in light from darkness to high or low light and showed that mesophyll conductance would impose a smaller limitation to photosynthesis under fluctuating light conditions, but both of mesophyll conductance and stomatal conductance would contribute to the limitation of photosynthesis during induction (Sakoda et al. 2021). Relevant factors that might contribute to variations in mesophyll conductance are carbonic anhydrase and aquaporins.

\section{Future Prospects}

The present rate of increase in crop yields is insufficient to keep pace with the rapid increase in the global population. Thus, the development of crops with higher yield by improving photosynthesis is essential if we are to meet future food and energy demands. Therefore, suitable approaches must be explored for generating more efficient plants with higher yield. Enhancement of leaf photosynthetic capacity would provide one attractive way of achieving increases in crop yield since plant growth depends largely on photosynthesis. In this review, we have highlighted crucial targets that could be manipulated to enhance crop productivity (Fig. 7). To date, research into finding new ways to increase crop yield has focused on improving steady-state photosynthesis. However, leaves in natural plant canopies experience a highly variable light environment over the course of a day. Thus, the improvements in photosynthesis and yield observed in model plants grown in constant growth chambers may not be completely transferrable to crop species under field conditions. Therefore, an understanding of the key factors operating in natural environments and responsible for increases in yield is essential if we are to achieve the maximum yield potential.

Furthermore, improving photosynthesis to increase food production ultimately means maximizing the photosynthetic efficiency of the crop canopy rather than that of an individual plant. One approach would be to alter the plant architecture and biochemistry and thus distribute irradiation more evenly throughout the canopy in order to achieve the highest conversion efficiency of solar radiation to biomass. Recent genome editing technologies have been progressing and they will enable easier and more precise manipulation of the photosynthesis process in crops. Our understanding of photosynthesis will help us to achieve our goal of sustainable food production. 


\section{References}

Ainsworth EA, Leakey ADB, Ort DR, Long SP (2008) FACE-ing the facts: inconsistencies and interdependence among field, chamber and modeling studies of elevated $\mathrm{CO}_{2}$ impacts on crop yield and food supply. New Phytol 179:5-9

Alexandratos N, Bruinsma J (2012) World agriculture towards 2030/2050: the 2012 revision. ESA Working paper No. 12-03. FAO, Rome

Allahverdiyeva Y, Mustila H, Ermakova M, Bersanini L, Richaud P, Ajlani G, Battchikova N, Cournac L, Aro EM (2013) Flavodiiron proteins Flv1 and Flv3 enable cyanobacterial growth and photosynthesis under fluctuating light. Proc Natl Acad Sci U S A 110:4111-4116

Armbruster U, Carrillo LR, Venema K, Pavlovic L, Schmidtmann E, Kornfeld A, Jahns P, Berry JA, Kramer DM, Jonikas MC (2014) Ion antiport accelerates photosynthetic acclimation in fluctuating light environments. Nat Commun 5:5439

Armbruster U, Leonelli L, Correa Galvis V, Strand D, Quinn EH, Jonikas MC, Niyogi KK (2016) Regulation and levels of the thylakoid $\mathrm{K}^{+} / \mathrm{H}^{+}$antiporter KEA3 shape the dynamic response of photosynthesis in fluctuating light. Plant Cell Physiol 57:1557-1567

Ballantyne AP, Alden CB, Miller JB, Tans PP, White JWC (2012) Increase in observed net carbon dioxide uptake by land and oceans during the last 50 years. Nature 488:70-72

Biswal AK, Pattanayak GK, Pandey SS, Leelavathi S, Reddy VS, Govindjee, Tripathy BC (2012) Light intensity-dependent modulation of chlorophyll $\mathrm{b}$ biosynthesis and photosynthesis by overexpression of chlorophyllide $a$ oxygenase in tobacco. Plant Physiol 159:433-449

Burkey KO (1994) Genetic variation of photosynthetic electron transport in barley: identification of plastocyanin as a potential limiting factor. Plant Sci 98:177-187

Burkey KO, Gizlice Z, Carter TE (1996) Genetic variation in soybean photosynthetic electron transport capacity is related to plastocyanin concentration in the chloroplast. Photosynth Res 49:141-149

Busch FA, Sage TL, Cousins AB, Sage RF (2013) $C_{3}$ plants enhance rates of photosynthesis by reassimilating photorespired and respired $\mathrm{CO}_{2}$. Plant Cell Environ 36:200-212

Carmo-Silva AE, Salvucci ME (2012) The temperature response of $\mathrm{CO}_{2}$ assimilation, photochemical activities and RuBisCO activation in Camelina sativa, a potential bioenergy crop with limited capacity for acclimation to heat stress. Planta 236:1433-1445

Carmo-Silva AE, Salvucci ME (2013) The regulatory properties of RuBisCO activase differ among species and affect photosynthetic induction during light transitions. Plant Physiol 161:1645-1655

Carraretto L, Formentin E, Teardo E, Checchetto V, Tomizioli M, Morosinotto T, Giacometti GM, Finazzi G, Szabó I (2013) A thylakoid-located two-pore K+ channel controls photosynthetic light utilization in plants. Science 342:114-118

Carvalho J, Madgwick P, Powers S, Keys A, Lea P, Parry M (2012) An engineered pathway for glyoxylate metabolism in tobacco plants aimed to avoid the release of ammonia in photorespiration. BMC Biotechnol 11:111

Chai MF, Chen QJ, An R, Chen YM, Chen J, Wang XC (2005) NADK2, an Arabidopsis chloroplastic NAD kinase, plays a vital role in both chlorophyll synthesis and chloroplast protection. Plant Mol Biol 59:553-564

Chen M, Blankenship RE (2011) Expanding the solar spectrum used by photosynthesis. Trends Plant Sci 16:427-431

Chen M, Schliep M, Willows RD, Cai Z-L, Neilan BA, Scheer H (2010) A red-shifted chlorophyll. Science 329:1318-1319

Chida H, Nakazawa A, Akazaki H, Hirano T, Suruga K, Ogawa M, Satoh T, Kadokura K, Yamada S, Hakamata W et al (2007) Expression of the algal cytochrome $c_{6}$ gene in Arabidopsis enhances photosynthesis and growth. Plant Cell Physiol 48:948-957

Covshoff S, Hibberd JM (2012) Integrating $\mathrm{C}_{4}$ photosynthesis into $\mathrm{C}_{3}$ crops to increase yield potential. Curr Opin Biotechnol 23:209-214 
Crafts-Brandner SJ, Salvucci ME (2000) Rubisco activase constrains the photosynthetic potential of leaves at high temperature and $\mathrm{CO}_{2}$. Proc Natl Acad Sci U S A 97:13430-13435

Ding F, Wang M, Zhang S, Ai X (2016) Changes in SBPase activity influence photosynthetic capacity, growth, and tolerance to chilling stress in transgenic tomato plants. Sci Rep 32741

Driever SM, Simkin AJ, Alotaibi S, Fisk SJ, Madgwick PJ, Sparks CA, Jones HD, Lawson T, Parry MAJ, Raines CA (2017) Increased SBPase activity improves photosynthesis and grain yield in wheat grown in greenhouse conditions. Philos Trans R Soc Lond B Biol Sci 372:20160384

Duan Z, Kong F, Zhang L, Li W, Zhang J, Peng L (2016) A bestrophin-like protein modulates the proton motive force across the thylakoid membrane in Arabidopsis. J Integr Plant Biol 58:848-858

Evans JR (1989) Photosynthesis and nitrogen relationships in leaves of $\mathrm{C}_{3}$ plants. Oecologia 78:9-19

Evans JR, Kaldenhoff R, Genty B, Terashima I (2009) Resistances along the $\mathrm{CO}_{2}$ diffusion pathway inside leaves. J Exp Bot 60:2235-2248

Farquhar GD, von Caemmerer S, Berry JA (1980) A biochemical model of photosynthetic $\mathrm{CO}_{2}$ assimilation in leaves of C3 species. Planta 149:78-90

Finazzi G, Petroutsos D, Tomizioli M, Flori S, Sautron E, Villanova V, Rolland N, SeigneurinBerny D (2015) Ions channels/transporters and chloroplast regulation. Cell Calcium 58:86-97

Flexas J, Ribas-Carbó M, Hanson DT, Bota J, Otto B, Cifre J, McDowell N, Medrano H, Kaldenhoff $\mathrm{R}$ (2006) Tobacco aquaporin NtAQP1 is involved in mesophyll conductance to $\mathrm{CO}_{2}$ in vivo. Plant J 48:427-439

Flexas J, Diaz-Espejo A, Galmés J, Kaldenhoff R, Medrano H, Ribas-Carbo M (2007) Rapid variations of mesophyll conductance in response to changes in $\mathrm{CO}_{2}$ concentration around leaves. Plant Cell Environ 30:1284-1298

Flexas J, Ribas-Carbó M, Diaz-Espejo A, Galmés J, Medrano H (2008) Mesophyll conductance to $\mathrm{CO}_{2}$ : current knowledge and future prospects. Plant Cell Environ 31:602-621

Flexas J, Barbour MM, Brendel O, Cabrera HM, Carriquí M, Diaz-Espejo A, Douthe C, Dreyer E, Ferrio JP, Gago J, Gallé A, Galmés J, Kodama N, Medrano H, Niinemets Ü, PegueroPina JJ, Pou A, Ribas-Carbó M, Tomás M, Tosens T, Warren CR, Gallé A (2012) Mesophyll diffusion conductance to $\mathrm{CO}_{2}$ : an unappreciated central player in photosynthesis. Plant Sci 193-194:70-84

Furbank RT, Quick WP, Sirault XR (2015) Improving photosynthesis and yield potential in cereal crops by targeted genetic manipulation: prospects, progress and challenges. Field Crops Res 182:19-29

Gotoh E, Suetsugu N, Yamori W, Ishishita K, Kiyabu R, Fukuda M, Higa T, Shirouchi B, Wada M (2018) Chloroplast accumulation response enhances leaf photosynthesis and plant biomass production. Plant Physiol 178:1358-1369

Gu J, Yin X, Stomph TJ, Struik PC (2014) Can exploiting natural genetic variation in leaf photosynthesis contribute to increasing rice productivity? A simulation analysis. Plant Cell Environ 37:22-34

Haake V, Zrenner R, Sonnewald U, Stitt M (1998) A moderate decrease of plastid aldolase activity inhibits photosynthesis, alters the levels of sugars and starch, and inhibits growth of potato plants. Plant J 14:147-157

Haake V, Geiger M, Walch-Liu P, Engels C, Zrenner R, Stitt M (1999) Changes in aldolase activity in wild-type potato plants are important for acclimation to growth irradiance and carbon dioxide concentration, because plastid aldolase exerts control over the ambient rate of photosynthesis across a range of growth conditions. Plant J 17:479-489

Hajirezaei M-R, Peisker M, Tschiersch H, Palatnik JF, Valle EM, Carrillo N, Sonnewald U (2002) Small changes in the activity of chloroplastic $\mathrm{NADP}^{+}$-dependent ferredoxin oxidoreductase lead to impaired plant growth and restrict photosynthetic activity of transgenic tobacco plants. Plant J 29:281-293

Hammond ET, Andrews TJ, Mott KA, Woodrow IE (1998) Regulation of Rubisco activation in antisense plants of tobacco containing reduced levels of Rubisco activase. Plant J 14:101-110

Hanba YT, Shibasaka M, Hayashi Y, Hayakawa T, Kasamo K, Terashima I, Katsuhara M (2004) Overexpression of the barley aquaporin HvPIP2; 1 increases internal $\mathrm{CO}_{2}$ conductance and $\mathrm{CO}_{2}$ assimilation in the leaves of transgenic rice plants. Plant Cell Physiol 45:521-529 
Harrison EP, Willingham NM, Lloyd JC, Raines CA (1998) Reduced sedoheptulose-1,7bisphosphatase levels in transgenic tobacco lead to decreased photosynthetic capacity and altered carbohydrate accumulation. Planta 204:27-36

Harrison EP, Olcer H, Lloyd JC, Long SP, Raines CA (2001) Small decreases in SBPase cause a linear decline in the apparent RuBP regeneration rate, but do not affect Rubisco carboxylation capacity. J Exp Bot 52:1779-1784

Hatano-Iwasaki A, Ogawa K (2012) Biomass production is promoted by increasing an aldolase undergoing glutathionylation in Arabidopsis thaliana. Int J Dev Biol 6:1-8

Hay WT, Bihmidine S, Mutlu N, Le Hoang K, Awada T, Weeks DP, Clemente TE, Long SP (2017) Enhancing soybean photosynthetic $\mathrm{CO}_{2}$ assimilation using a cyanobacterial membrane protein, ictB. J Plant Physiol 212:58-68

Heckwolf M, Pater D, Hanson DT, Kaldenhoff R (2011) The Arabidopsis thaliana aquaporin AtPIP1;2 is a physiologically relevant $\mathrm{CO}_{2}$ transport facilitator. Plant J 67:795-804

Herdean A, Teardo E, Nilsson AK, Pfeil BE, Johansson ON, Ünnep R, Nagy G, Zsiros O, Dana S, Solymosi K, Garab G (2016) A voltage-dependent chloride channel fine-tunes photosynthesis in plants. Nat Commun 7:11654

Hisabori T, Sunamura E, Kim Y, Konno H (2013) The chloroplast ATP synthase features the characteristic redox regulation machinery. Antioxid Redox Signal 19:1846-1854

IPCC (2013) Annex II: climate system scenario tables. In: Prather M, Flato G, Friedlingstein P et al (eds) Climate change 2013: the physical science basis. Contribution of Working Group I to the fifth assessment report of the Intergovernmental Panel on Climate Change. Cambridge University Press, Cambridge

Ishikawa C, Hatanaka T, Misoo S, Miyake C, Fukayama H (2011) Functional incorporation of sorghum small subunit increases the catalytic turnover rate of RuBisCO in transgenic rice. Plant Physiol 156:1603-1611

Kaiser E, Morales A, Harbinson J, Heuvelink E, Prinzenberg AE, Marcelis LFM (2016) Metabolic and diffusional limitations of photosynthesis in fluctuating irradiance in Arabidopsis thaliana. Sci Rep 6:31252

Kaldenhoff $\mathrm{R}$ (2012) Mechanisms underlying $\mathrm{CO}_{2}$ diffusion in leaves. Curr Opin Plant Biol $15: 276-281$

Kawai S, Murata K (2008) Structure and function of NAD kinase and NADP phosphatase: key enzymes that regulate the intracellular balance of $\mathrm{NAD}(\mathrm{H})$ and $\mathrm{NADP}(\mathrm{H})$. Biosci Biotechnol Biochem 72:919-930

Kebeish R, Niessen M, Thiruveedhi K, Bari R, Hirsch HJ, Rosenkranz R, Stäbler N, Schönfeld B, Kreuzaler F, Peterhänsel C (2007) Chloroplastic photorespiratory bypass increases photosynthesis and biomass production in Arabidopsis thaliana. Nat Biotechnol 25:593-599

Kimura H, Hashimoto-Sugimoto M, Iba K, Terashima I, Yamori W (2020) Improved stomatal opening enhances photosynthetic rate and biomass production in fluctuating light. J Exp Bot 71:2339-2350

Köhler IH, Ruiz-Vera UM, VanLoocke A, Thomey ML, Clemente T, Long SP, Ort DR, Bernacchi CJ (2016) Expression of cyanobacterial FBP/SBPase in soybean prevents yield depression under future climate conditions. J Exp Bot 68:715-726

Kossmann J, Sonnewald U, Willmitzer L (1994) Reduction of the chloroplastic fructose-1,6bisphosphatase in transgenic potato plants impairs photosynthesis and plant growth. Plant $\mathrm{J}$ 6:637-650

Kozaki A, Takeba G (1996) Photorespiration protects $\mathrm{C}_{3}$ plants from photooxidation. Nature 384:557

Kramer DM, Cruz JA, Kanazawa A (2003) Balancing the central roles of the thylakoid proton gradient. Trends Plant Sci 8:27-32

Kromdijk J, Głowacka K, Leonelli L, Gabilly ST, Iwai M, Niyogi KK, Long SP (2016) Improving photosynthesis and crop productivity by accelerating recovery from photoprotection. Science 354:857-861

Kumar A, Li C, Portis AR Jr (2009) Arabidopsis thaliana expressing a thermostable chimeric Rubisco activase exhibits enhanced growth and higher rates of photosynthesis at moderately high temperatures. Photosynth Res 100:143-153 
Kunz HH, Gierth M, Herdean A, Satoh-Cruz M, Kramer DM, Spetea C, Schroeder JI (2014) Plastidial transporters KEA1, -2 , and -3 are essential for chloroplast osmoregulation, integrity, and $\mathrm{pH}$ regulation in Arabidopsis. Proc Natl Acad Sci U S A 111:7480-7485

Kurek I, Chang TK, Bertain SM, Madrigal A, Liu L, Lassner MW, Zhu G (2007) Enhanced thermostability of Arabidopsis rubisco activase improves photosynthesis and growth rates under moderate heat stress. Plant Cell 19:3230-3241

Kusumi K, Hirotsuka S, Kumamaru T, Iba K (2012) Increased leaf photosynthesis caused by elevated stomatal conductance in a rice mutant deficient in SLAC1, a guard cell anion channel protein. J Exp Bot 63:5635-5644

Lawson T, Blatt MR (2014) Stomatal size, speed, and responsiveness impact on photosynthesis and water use efficiency. Plant Physiol 164:1556-1570

Lawson T, Bryant B, Lefebvre S, Lloyd JC, Raines CA (2006) Decreased SBPase activity alters growth and development in transgenic tobacco plants. Plant Cell Environ 29:48-58

Lefebvre S, Lawson T, Zakhleniuk OV, Lloyd JC, Raines CA, Fryer M (2005) Increased sedoheptulose-1,7-bisphosphatase activity in transgenic tobacco plants stimulates photosynthesis and growth from an early stage in development. Plant Physiol 138:451-460

Lieman-Hurwitz J, Rachmilevitch S, Mittler R, Marcus Y, Kaplan A (2003) Enhanced photosynthesis and growth of transgenic plants that express ictB, a gene involved in $\mathrm{HCO}_{3}{ }^{-}$accumulation in cyanobacteria. Plant Biotechnol J 1:43-50

Lin MT, Occhialini A, Andralojc PJ, Parry MAJ, Hanson MR (2014) A faster Rubisco with potential to increase photosynthesis in crops. Nature 513:547-550

Long BM, Hee WY, Sharwood RE, Rae BD, Kaines S, Lim YL, Nguyen ND, Massey B, Bala S, von Caemmerer S, Badger MR (2018) Carboxysome encapsulation of the $\mathrm{CO}_{2}$-fixing enzyme Rubisco in tobacco chloroplasts. Nat Commun 9:3570

Lopez-Calcagno PE, Fisk S, Brown KL, Bull SE, South PF, Raines CA (2018) Overexpressing the H-protein of the glycine cleavage system increases biomass yield in glasshouse and field grown transgenic tobacco plants. Plant Biotechnol J 17(1):141-151. https://doi.org/10.1111/ pbi. 12953

Maier A, Fahnenstich H, von Caemmerer S, Engqvist MKM, Weber APM, Fluegge U-I, Maurino VG (2012) Transgenic introduction of a glycolate oxidative cycle into A. thaliana chloroplasts leads to growth improvement. Front. Plant Sci 3:38

Makino A, Sato T, Nakano H, Mae T (1997) Leaf photosynthesis, plant growth and nitrogen allocation in rice under different irradiances. Planta 203:390-398

Masumoto C, Fukayama H, Hatanaka T, Uchida N (2012) Photosynthetic characteristics of antisense transgenic rice expressing reduced levels of Rubisco activase. Plant Prod Sci 15:174-182

Miginiac-Maslow M, Johansson K, Ruelland E, Issakidis-Bourguet E, Schepens I, Goyer A, Lemaire-Chamley M, Jacquot J-P, Le Maréchal P, Decottignies P (2000) Light-activation of NADP-malate dehydrogenase: a highly controlled process for an optimized function. Physiol Plant 110:322-329

Miyagawa Y, Tamoi M, Shigeoka S (2001) Overexpression of a cyanobacterial fructose-1,6-/ sedoheptulose-1,7-bisphosphatase in tobacco enhances photosynthesis and growth. Nat Biotechnol 19:965-969

Miyashita H, Ikemoto H, Kurano N, Adachi K, Chihara M, Miyachi S (1996) Chlorophyll $d$ as a major pigment. Nature 383:402-402

Morris PF, Layzell DB, Canvin DT (1988) Ammonia production and assimilation in glutamate synthase mutants of Arabidopsis thaliana. Plant Physiol 87:148-154

Mott KA, Snyder GW, Woodrow IE (1997) Kinetics of Rubisco activation as determined from gasexchange measurements in antisense plants of Arabidopsis thaliana containing reduced levels of Rubisco activase. Aust J Plant Physiol 24:811-818

Mueller-Cajar O, Stotz M, Wendler P, Hartl FU, Bracher A, Hayer-Hartl M (2011) Structure and function of the AAA+ protein CbbX, a red-type Rubisco activase. Nature 479:194-199

Murchie EH, Niyogi KK (2011) Manipulation of photoprotection to improve plant photosynthesis. Plant Physiol 155:86-92 
Naumburg E, Ellsworth DS (2002) Short-term light and leaf photosynthetic dynamics affect estimates of daily understory photosynthesis in four tree species. Tree Physiol 22:393-401

Nikkanen L, Toivola J, Rintamäki E (2016) Crosstalk between chloroplast thioredoxin systems in regulation of photosynthesis. Plant Cell Environ 39:1691-1705

Ölcer H, Lloyd JC, Raines CA (2001) Photosynthetic capacity is differentially affected by reductions in sedoheptulose-1,7-bisphosphatase activity during leaf development in transgenic tobacco plants. Plant Physiol 125:982-989

Papanatsiou M, Petersen J, Henderson L, Wang Y, Christie JM, Blatt MR (2019) Optogenetic manipulation of stomatal kinetics improves carbon assimilation, water use, and growth. Science 363:1456-1459

Parry MAJ, Keys AJ, Madgwick PJ, Carmo-Silva AE, Andralojc PJ (2008) Rubisco regulation: a role for inhibitors. J Exp Bot 59:1569-1580

Pearcy RW (1990) Sunflecks and photosynthesis in plant canopies. Annu Rev Plant Physiol Plant Mol Biol 41:421-453

Pesaresi P, Scharfenberg M, Weigel M, Granlund I, Schroder WP, Finazzi G, Rappaport F, Masiero S, Furini A, Jahns P, Leister D (2009) Mutants, overexpressors, and interactors of Arabidopsis plastocyanin isoforms: revised roles of plastocyanin in photosynthetic electron flow and thylakoid redox state. Mol Plant 2:236-248

Peterhansel C, Blume C, Offermann S (2013) Photorespiratory bypasses: how can they work? J Exp Bot 64:709-715

Portis AR Jr (2003) Rubisco activase: Rubisco's catalytic chaperone. Photosynth Res 75:11-27

Pribil M, Pesaresi P, Hertle A, Barbato R, Leister D (2010) Role of plastid protein phosphatase TAP38 in LHCII dephosphorylation and thylakoid electron flow. PLoS Biol 8:e1000288

Price GD, von Caemmerer S, Evans JR, Siebke K, Anderson JM, Badger MR (1998) Photosynthesis is strongly reduced by antisense suppression of chloroplastic cytochrome $b f$ complex in transgenic tobacco. Funct Plant Biol 25:445-452

Price GD, Badger MR, von Caemmerer S (2011) The prospect of using cyanobacterial bicarbonate transporters to improve leaf photosynthesis in $\mathrm{C}_{3}$ crop plants. Plant Physiol 155:20-26

Price GD, Pengelly JJL, Forster B, Du J, Whitney SM, von Caemmerer S, Badger MR, Howitt SM, Evans JR (2013) The cyanobacterial CCM as a source of genes for improving photosynthetic $\mathrm{CO}_{2}$ fixation in crop species. J Exp Bot 64:753-768

Raines CA (2003) The Calvin cycle revisited. Photosynth Res 75:1-10

Raines CA, Paul MJ (2006) Products of leaf primary carbon metabolism modulate the developmental programme determining plant morphology. J Exp Bot 57:1857-1862

Raines CA, Lloyd JC, Dyer TA (1999) New insights into the structure and function of sedoheptulose-1,7-bisphosphatase; an important but neglected Calvin cycle enzyme. J Exp Bot 50:1-8

Richards RA (2000) Selectable traits to increase crop photosynthesis and yield of grain crops. J Exp Bot 51:447-458

Rodriguez RE, Lodeyro A, Poli HO, Zurbriggen M, Palatnik JF, Tognetti VB, Tschiersch H, Hajirezaei MR, Valle EM, Carrillo N (2007) Transgenic tobacco plants overexpressing chloroplastic ferredoxin-NADP $(\mathrm{H})$ reductase display normal rates of photosynthesis and increased tolerance to oxidative stress. Plant Physiol 143:639-649

Rojas-González JA, Soto-Súarez M, García-Díaz Á, Romero-Puertas MC, Sandalio LM, Mérida Á, Thormählen I et al (2015) Disruption of both chloroplastic and cytosolic FBPase genes results in a dwarf phenotype and important starch and metabolite changes in Arabidopsis thaliana. J Exp Bot 66:2673-2689

Rosenthal D, Locke A, Khozaei M, Raines C, Long S, Ort D (2011) Over-expressing the $\mathrm{C}_{3}$ photosynthesis cycle enzyme sedoheptulose-1-7 bisphosphatase improves photosynthetic carbon gain and yield under fully open air $\mathrm{CO}_{2}$ fumigation (FACE). BMC Plant Biol 11:123

Sage RF, Sage TL, Kocacinar F (2012) Photorespiration and the evolution of $\mathrm{C}_{4}$ photosynthesis. Annu Rev Plant Biol 63:19-47 
Sakoda K, Yamori W, Groszmann M, Evans JR (2021) Stomatal, mesophyll conductance, and biochemical limitations to photosynthesis during induction. Plant Physiology

Sahrawy M, Avila C, Chueca A, Canovas FM, Lopez-Gorge J (2004) Increased sucrose level and altered nitrogen metabolism in Arabidopsis thaliana transgenic plants expressing antisense chloroplastic fructose-1,6-bisphosphatase. J Exp Bot 55:2495-2503

Salvucci ME, Crafts-Brandner SJ (2004a) Relationship between the heat tolerance of photosynthesis and the thermal stability of Rubisco activase in plants from contrasting thermal environments. Plant Physiol 134:1460-1470

Salvucci ME, Crafts-Brandner SJ (2004b) Inhibition of photosynthesis by heat stress: the activation state of Rubisco as a limiting factor in photosynthesis. Physiol Plant 120:179-186

Salvucci ME, DeRidder BP, Portis AR (2006) Effect of activase level and isoform on the thermotolerance of photosynthesis in Arabidopsis. J Exp Bot 57:3793-3799

Sanz-Barrio R, Corral-Martinez P, Ancin M, Segui-Simarro JM, Farran I (2013) Overexpression of plastidial thioredoxin $\mathrm{f}$ leads to enhanced starch accumulation in tobacco leaves. Plant Biotechnol J 11:618-627

Scafaro AP, Atwell BJ, Muylaert S, Van Reusel B, Alguacil Ruiz G, Van Rie J, Gallé A (2018) A thermotolerant variant of Rubisco activase from a wild relative improves growth and seed yield in rice under heat stress. Front Plant Sci 9:1663

Schöttler MA, Kirchhoff H, Weis E (2004) The role of plastocyanin in the adjustment of the photosynthetic electron transport to the carbon metabolism in tobacco. Plant Physiol 136:4265-4274

Shimadzu S, Seo M, Terashima I, Yamori W (2019) Whole irradiated plant leaves showed faster photosynthetic induction than individually irradiated leaves via improved stomatal opening. Front Plant Sci 10:1512

Simkin AJ, McAusland L, Lawson T, Raines CA (2017) Over-expression of the Rieske FeS protein increases electron transport rates and biomass yield. Plant Physiol 175:134-145

Sinclair TR, Purcell LC, Sneller CH (2004) Crop transformation and the challenge to increase yield potential. Trends Plant Sci 9:70-75

Spreitzer RJ, Salvucci ME (2002) Rubisco: structure, regulatory interactions, and possibilities for a better enzyme. Annu Rev Plant Biol 53:449-475

Stotz M, Mueller-Cajar O, Ciniawsky S, Wendler P, Hartl FU, Bracher A, Hayer-Hartl M (2011) Structure of green-type RuBisCO activase from tobacco. Nat Struct Mol Biol 18:1366-1370

Takahara K, Kasajima I, Takahashi H, Hashida SN, Itami T, Onodera H, Toki S, Yanagisawa S, Kawai-Yamada M, Uchimiya H (2010) Metabolome and photochemical analysis of rice plants overexpressing Arabidopsis NAD kinase gene. Plant Physiol 152:1863-1873

Tamoi M, Nagaoka M, Miyagawa Y, Shigeoka S (2006) Contribution of fructose-1,6-bisphosphatase and sedoheptulose-1,7-bisphosphatase to the photosynthetic rate and carbon flow in the Calvin cycle in transgenic plants. Plant Cell Physiol 47:380-390

Tanaka Y, Sugano SS, Shimada T, Hara-Nishimura I (2013) Enhancement of leaf photosynthetic capacity through increased stomatal density in Arabidopsis. New Phytol 198:757-764

Tanaka Y, Adachi S, Yamori W (2019) Natural genetic variation of the photosynthetic induction response to fluctuating light environment. Curr Opin Plant Biol 49:52-59

Taylor SH, Long SP (2017) Slow induction of photosynthesis on shade to sun transitions in wheat may cost at least $21 \%$ of productivity. Philos Trans R Soc Lond B Biol Sci 372:20160543

Tazoe Y, von Caemmerer S, Estavillo GM, Evans JR (2011) Using tunable diode laser spectroscopy to measure carbon isotope discrimination and mesophyll conductance to $\mathrm{CO}_{2}$ diffusion dynamically at different $\mathrm{CO}_{2}$ concentrations. Plant Cell Environ 344:580-591

Terashima I, Hanba YT, Tholen D, Niinemets Ü (2011) Leaf functional anatomy in relation to photosynthesis. Plant Physiol 155:108-116

Tholen D, Zhu XG (2011) The mechanistic basis of internal conductance: a theoretical analysis of mesophyll cell photosynthesis and $\mathrm{CO}_{2}$ diffusion. Plant Physiol 156:90-105

Tholen D, Boom C, Noguchi K, Ueda S, Katase T, Terashima I (2008) The chloroplast avoidance response decreases internal conductance to $\mathrm{CO}_{2}$ diffusion in Arabidopsis thaliana leaves. Plant Cell Environ 31:1688-1700 
Thormählen I, Ruber J, von Roepenack-Lahaye E, Ehrlich S, Massot V, Huemmer C, Tezycka J, Issakidis-Bourguet E, Geigenberger P (2013) Inactivation of thioredoxin $\mathrm{f} 1$ leads to decreased light activation of ADP-glucose pyrophosphorylase and altered diurnal starch turnover in leaves of Arabidopsis plants. Plant Cell Environ 36:16-29

Thormählen I, Zupok A, Rescher J, Leger J, Weissenberger S, Groysman J, Orwat A, ChatelInnocenti G, Issakidis-Bourguet E, Armbruster U et al (2017) Thioredoxins play a crucial role in dynamic acclimation of photosynthesis in fluctuating light. Mol Plant 10:168-182

Tikkanen M, Grieco M, Nurmi M, Rantala M, Suorsa M, Aro EM (2012) Regulation of the photosynthetic apparatus under fluctuating growth light. Philos Trans R Soc Lond B Biol Sci 367:3486-3493

Tilman D, Balzer C, Hill J, Befort BL (2011) Global food demand and the sustainable intensification of agriculture. Proc Natl Acad Sci U S A 108:20260-20264

Timm S, Florian A, Arrivault S, Stitt M, Fernie AR, Bauwe H (2012) Glycine decarboxylase controls photosynthesis and plant growth. FEBS Lett 586:3692-3697

Timm S, Wittmiss M, Gamlien S, Ewald R, Florian A, Frank M, Wirtz M et al (2015) Mitochondrial dihydrolipoyl dehydrogenase activity shapes photosynthesis and photorespiration of Arabidopsis thaliana. Plant Cell 27:1968-1984

Timm S, Florian A, Fernie AR, Bauwe H (2016) The regulatory interplay between photorespiration and photosynthesis. J Exp Bot 67:2923-2929

Toivola J, Nikkanen L, Dahlström KM, Salminen TA, Lepistö A, Vignols F, Rintamäki E (2013) Overexpression of chloroplast NADPH-dependent thioredoxin reductase in Arabidopsis enhances leaf growth and elucidates in vivo function of reductase and thioredoxin domains. Front Plant Sci 4:389

Uehlein N, Sperling H, Heckwolf M, Kaldenhoff R (2012) The Arabidopsis aquaporin PIP1;2 rules cellular $\mathrm{CO}_{2}$ uptake. Plant Cell Environ 35:1077-1083

Uematsu K, Suzuki N, Iwamae T, Inui M, Yukawa H (2012) Increased fructose 1,6-bisphosphate aldolase in plastids enhances growth and photosynthesis of tobacco plants. J Exp Bot 63:3001-3009

Vialet-Chabrand SRM, Matthews JSA, McAusland L, Blatt MR, Griffiths H, Lawson T (2017) Temporal dynamics of stomatal behavior: modeling and implications for photosynthesis and water use. Plant Physiol 174:603-613

von Caemmerer S, Quick WP, Furbank RT (2012) The development of $\mathrm{C}_{4}$ rice: current progress and future challenges. Science 336:1671-1672

Wada S, Yamamoto H, Suzuki Y, Yamori W, Shikanai T, Makino A (2018) Flavodiiron protein substitutes for cyclic electron flow without competing $\mathrm{CO}_{2}$ assimilation in rice. Plant Physiol 176:1509-1518

Walker BJ, VanLoocke A, Bernacchi CJ, Ort DR (2016) The costs of photorespiration to food production now and in the future. Annu Rev Plant Biol 67:107-129

Whitney SM, Sharwood RE, Orr D, White SJ, Alonso H, Galmés J (2011) Isoleucine 309 acts as $\mathrm{a} \mathrm{C}_{4}$ catalytic switch that increases ribulose-1,5-bisphosphate carboxylase/oxygenase (rubisco) carboxylation rate in Flaveria. Proc Natl Acad Sci U S A 108:14688-14693

Wigge B, Krömer S, Gardeström P (1993) The redox levels and subcellular distribution of pyridine nucleotides in illuminated barley leaf protoplasts studied by rapid fractionation. Physiol Plant 88:10-18

Wright IJ, Reich PB, Westoby M, Ackerly DD, Baruch Z et al (2004) The worldwide leaf economics spectrum. Nature 428:821-827

Yamamoto H, Kato H, Shinzaki Y, Horiguchi S, Shikanai T, Hase T, Endo T, Nishioka M, Makino A, Tomizawa K, Miyake C (2006) Ferredoxin limits cyclic electron flow around PSI (CEFPSI) in higher plants: stimulation of CEF-PSI enhances non-photochemical quenching of Chl fluorescence in transplastomic tobacco. Plant Cell Physiol 47:1355-1371

Yamamoto H, Takahashi S, Badger MR, Shikanai T (2016) Artificial remodelling of alternative electron flow by flavodiiron proteins in Arabidopsis. Nat Plants 2:16012 
Yamori W (2016) Photosynthetic response to fluctuating environments and photoprotective strategies under abiotic stress. J Plant Res 129:379-395

Yamori W, Shikanai T (2016) Physiological functions of cyclic electron transport around photosystem I in sustaining photosynthesis and plant growth. Annu Rev Plant Biol 67:81-106

Yamori W, von Caemmerer S (2009) Effect of Rubisco activase deficiency on the temperature response of $\mathrm{CO}_{2}$ assimilation rate and Rubisco activation state: insights from transgenic tobacco with reduced amounts of Rubisco activase. Plant Physiol 151:2073-2082

Yamori W, Noguchi K, Hanba YT, Terashima I (2006a) Effects of internal conductance on the temperature dependence of the photosynthetic rate in spinach leaves from contrasting growth temperatures. Plant Cell Physiol 47:1069-1080

Yamori W, Suzuki K, Noguchi K, Nakai M, Terashima I (2006b) Effects of Rubisco kinetics and Rubisco activation state on the temperature dependence of the photosynthetic rate in spinach leaves from contrasting growth temperatures. Plant Cell Environ 29:1659-1670

Yamori W, Takahashi S, Makino A, Price GD, Badger MR, von Caemmerer S (2011) The roles of ATP synthase and the cytochrome $b_{f} / f$ complexes in limiting chloroplast electron transport and determining photosynthetic capacity. Plant Physiol 155:956-962

Yamori W, Masumoto C, Fukayama H, Makino A (2012) Rubisco activase is a key regulator of non-steady-state photosynthesis at any leaf temperature and, to a lesser extent, of steady-state photosynthesis at high temperature. Plant J 71:871-880

Yamori W, Hikosaka K, Way DA (2014) Temperature response of photosynthesis in $\mathrm{C}_{3}, \mathrm{C}_{4}$ and CAM plants: temperature acclimation and temperature adaptation. Photosynth Res 119:101-117

Yamori W, Kondo E, Sugiura D, Terashima I, Suzuki Y, Makino A (2016a) Enhanced leaf photosynthesis as a target to increase grain yield: insights from transgenic rice lines with variable Rieske FeS protein content in the cytochrome b6/f complex. Plant Cell Environ 39:80-87

Yamori W, Irving LJ, Adachi S, Busch FA (2016b) Strategies for optimizing photosynthesis with biotechnology to improve crop yield. In: Pessarakli M (ed) Handbook of photosynthesis, 3rd edn. Taylor \& Francis, Boca Raton, pp 741-759

Yamori W, Makino A, Shikanai T (2016c) A physiological role of cyclic electron transport around photosystem I in sustaining photosynthesis under fluctuating light in rice. Sci Rep 6:20147

Yamori W, Kusumi K, Iba K, Terashima I (2020) Increased stomatal conductance induces rapid changes to photosynthetic rate in response to naturally fluctuating light conditions in rice. Plant Cell Environ 43:1230-1240

Open Access This chapter is licensed under the terms of the Creative Commons Attribution 4.0 International License (http://creativecommons.org/licenses/by/4.0/), which permits use, sharing, adaptation, distribution and reproduction in any medium or format, as long as you give appropriate credit to the original author(s) and the source, provide a link to the Creative Commons license and indicate if changes were made.

The images or other third party material in this chapter are included in the chapter's Creative Commons license, unless indicated otherwise in a credit line to the material. If material is not included in the chapter's Creative Commons license and your intended use is not permitted by statutory regulation or exceeds the permitted use, you will need to obtain permission directly from the copyright holder.

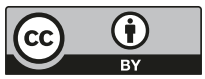

